
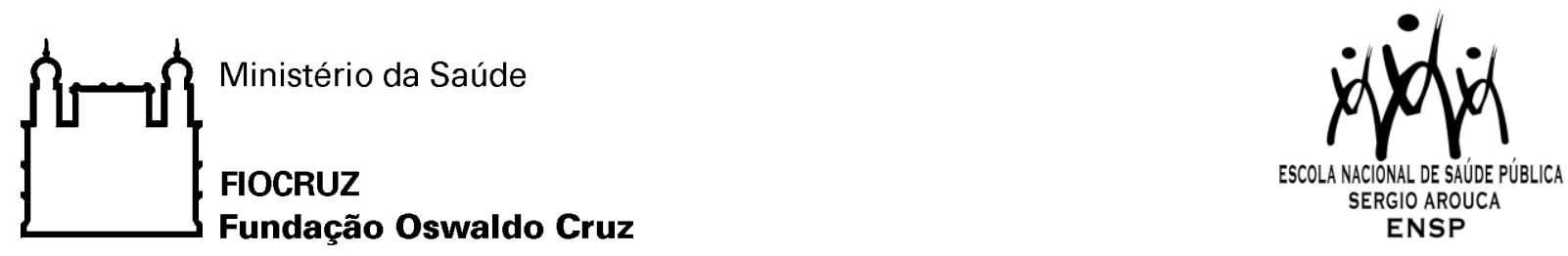

Andréa Fernanda Lopes dos Santos

"Prática Alimentar e Diabetes: Desafios para a Vigilância em Saúde"

Rio de Janeiro - RJ

Novembro - 2008 

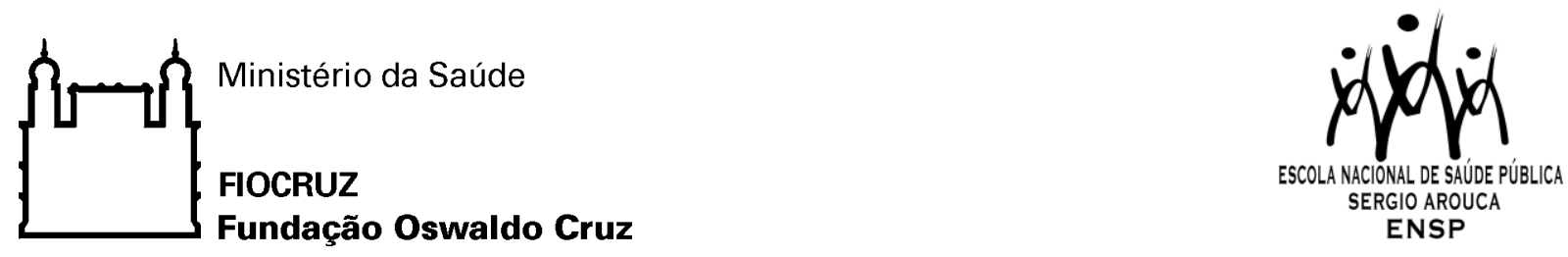

"Prática Alimentar e Diabetes: Desafios para a Vigilância em Saúde"

por

Andréa Fernanda Lopes dos Santos

Dissertação apresentada com vistas à obtenção do título de Mestre Modalidade Profissional em Saúde Pública.

Orientador: Prof. Dr. José Wellington Gomes Araújo

Rio de Janeiro, novembro de 2008. 

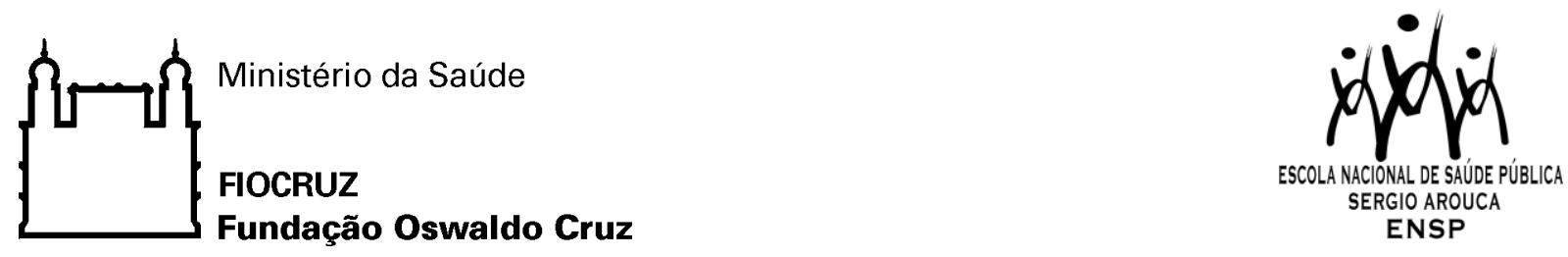

Esta dissertação, intitulada

"Prática Alimentar e Diabetes: desafios para a Vigilância em Saúde"

apresentada por

Andréa Fernanda Lopes dos Santos

foi avaliada pela Banca Examinadora composta pelos seguintes membros:

Prof. ${ }^{a}$ Dr. ${ }^{a}$ Vera Joana Bornstein

Prof. Dr. José Fernando de Souza Verani

Prof. Dr. José Wellington Gomes Araújo - Orientador 


\section{Catalogação na Fonte}

Instituto de comunicação e Informação Científica e Tecnológica

Biblioteca de Saúde Pública

\section{S237 Santos, Andréa Fernanda Lopes dos}

Prática alimentar e diabetes: desafios para a vigilância em saúde. / Andréa Fernanda Lopes dos Santos. Rio de Janeiro : s.n., 2009.

65 p., tab.

Orientador: Araújo, José Wellington Gomes de

Dissertação de Mestrado apresentada à Escola Nacional de

Saúde Pública Sergio Arouca 
Dedico ao meu irmão Afonso Junior (in memorian) que no início deste percurso partiu e não pode concluir a sua dissertação de Mestrado deixando saudades mas a certeza de reencontros em outros planos. 


\section{AGRADECIMENTOS}

Ao término de uma intensa jornada como esta há muitos a quem agradecer. Pessoas que, de diversas maneiras, deram seu carinho, atenção e contribuição para que este trabalho pudesse ser construído. A todos, meu muito obrigado.

A Deus fonte de toda a sabedoria que ilumina todos os passos humanos e os descobrimentos da ciência, pois só Ele tem a ciência da vida.

Aos meus familiares, em especial a minha mãe Irismar e a minha tia Irene Milhomem pelo incentivo e apoio.

Aos primos Clifton Angeline e Amanda Lobão pelo apoio de todas as horas.

Ao professor orientador José Wellington, pela leveza e solidariedade com que conduziu nossa relação orientando-orientador e pelos momentos de reflexão que me permitiu o exercício da liberdade intelectual.

Aos professores José Fernando de Souza Verani e Maria Beatriz Lisboa Guimarães pelo incentivo, colaboração e fecunda troca de idéias no exame de qualificação.

Meu carinho e gratidão especial às coordenadoras do mestrado Silvana Granado, Ines Mattos e Elsie Kubrusly pela acolhida e incentivo.

Aos professores do curso de mestrado da ENSP, atores desta história, que consolidaram conhecimentos e que despertaram em mim o prazer de aprender sobre Vigilância em Saúde.

A minha turma de mestrado do Ceará e Alagoas, amigos guardados para sempre em minha memória, com os quais vivi os desafios e alegrias de estar mestranda. Meu carinho especial para a Iracema, Zélia e a Dina.

Aos amigos de viagem, Augusto Cesar, Carlos, Claudia, Edna e Zenira por compartilharmos todos os momentos durante este tempo com o bom humor indispensável à disciplina intelectual. À Zenira, minha admiração e agradecimento pela sua amizade, paciência e solidariedade.

À minha amiga-irmã Sany e a afilhada Stefany pelo apoio, carinho e acolhida na cidade de Fortaleza.

À minha amiga Zélia Madeira pelo incentivo e que em muitos momentos contribuiu valorosamente com sua sensibilidade, idéias, debates e reflexões sobre a pesquisa.

Aos amigos e colegas da Gerência de Epidemiologia da Fundação Municipal de Saúde de Teresina, onde tive total apóio para a realização deste curso: Dra Amaríles Borba, Dra Amparo Salmito e Dr. Kelsen Eulálio, meu muito obrigado. 
A Faculdade NOVAFAPI, meu agradecimento sincero pela oportunidade de conviver, aprender e ensinar com vocês.

Ao amigo Kenard Kruel e ao Prof. Matias Matos pela atenção e colaboração com a literatura piauiense que me ajudou a encontrar o rumo e sedimentar o conteúdo deste estudo. história.

À Renata Carine, Claudia e Miriam, colegas nutricionistas que fazem parte desta

À Benevina Villar e Luciana Pereira (Faculdade NOVAFAPI), Silvana Carvalho (Hospital Getúlio Vargas) e Dr. Álvaro Regino pelo apoio e incentivo. estudo.

Às colegas Carmem Ramos e Theonas Gomes pelas observações e contribuições ao

Ao Oscar Briozo e ao Walberth Carvalho da Fundação Municipal de Saúde, pela paciência e apoio.

À turma da torcida e oração: Deusa, Andréia Marcia, Rose, Eliza, Chaguinha e De Deus, minha gratidão.

Agradeço imensamente a Deus que nos direciona em caminhos e coloca em nossas vidas pessoas especiais: Augusto, meu carinho.

Por fim, agradeço a todos aqueles com os quais efetuei trocas em uma trajetória construída passo a passo, entre idas e vindas, desfechos e retomadas que me proporcionou amadurecimento pessoal e profissional. A estes vários parceiros, minha amizade e gratidão. 
"O saber deve ser como um Rio, cujas águas doces, grossas, copiosas, transbordam do indivíduo, e se espraiem, estancando a sede dos outros". 


\section{RESUMO}

Importantes mudanças marcaram o perfil epidemiológico do Brasil nas últimas décadas, principalmente a diminuição das doenças infecciosas e parasitárias e o aumento das doenças crônicas não transmissíveis. Dentre estas o Diabetes Mellitus que, com uma prevalência alta e ascendente, limita a qualidade de vida de milhões de brasileiros, além de contribuir fortemente para o incremento das taxas de mortalidade, seja como causa básica ou associada. O Diabetes Mellitus configura-se, portanto, como um problema prioritário para a saúde pública do país. Para os profissionais que lidam com este problema é notória a dificuldade que as pessoas têm para mudar os seus hábitos alimentares, orientação geralmente requerida na terapia anti-diabética. E assim o presente estudo tem por objetivo investigar as dificuldades de mudanças de praticas alimentares de pessoas com Diabetes Mellitus, buscando compreender suas percepções, experiências e valores associados à alimentação. Com os resultados esperase poder subsidiar uma prática profissional dialogada e humanizada, de acordo com a atual política de Vigilância da Saúde. O estudo considera a diversidade cultural da alimentação e as realidades locais, esperando assim contribuir para uma prevenção e controle mais efetivos da doença. O universo estudado foram pessoas com Diabetes Mellitus tipo 2, atendidas no consultório de nutrição do ambulatório integrado de saúde Dirceu Mendes Arcoverde Hospital Getulio Vargas, em Teresina, Piauí. Para análise e compreensão do problema, foi utilizado o método da pesquisa qualitativa, através de entrevista semi-estruturada. O estudo possibilitou compreender as práticas alimentares em sua multidimensionalidade: cultura, tradição e identidade coletiva e individual. Estas valorações, quando não consideradas pelos profissionais, dificultam a relação com as pessoas portadoras da doença, que tenderão a negar o problema, não aderindo satisfatoriamente ao plano dieto-terápico. Além destes valores culturais e afetivos, também as limitações econômicos interferem na adesão das pessoas ao tratamento dietético. O estudo detectou o uso corrente e frequente da medicina popular na tentativa de cura ou melhora da doença. A partir das constatações, podemos contribuir para a Vigilância em Saúde, conhecendo aspectos subjetivos da realidade com foco regionalizado e ter subsídios para intervenções educativas e nutricionais eficazes na promoção, prevenção e educação em saúde.

Palavras-chave: Prática alimentar, Diabetes Mellitus, Educação em Saúde, Vigilância em Saúde 


\begin{abstract}
Important changes marked the epidemiological profile of Brazil in the last decades, principally the decrease of the infectious and parasitic diseases and the increase of the non transmittable chronic diseases. Among these, besides contributing strongly to the growth of the taxes of mortality, Diabetes Mellitus that, with a high and rising predominance, limits the quality of life of million Brazilians, being a basic or an associate cause. Diabetes Mellitus is shaped, so, like a priority problem for the public health of the country. For the professionals who deal with this problem, it is obvious the difficulty individuals have to change their food habits, direction generally applied in the anti-diabetic therapy. And so the present study aims to investigate the difficulties in changing food practices of patients with Diabetes Mellitus, trying to understand their perceptions, experiences and values associated to the food. It is expected from the results to be able to subsidize a professional dialogued and humanized practice, in accordance with the current policy of Drug and Food Association. The study considers the cultural diversity of the food and the local reality, hoping to contribute to a more effective prevention and control of the disease. The subjects studied were patients with Diabetes Mellitus type 2, assisted in the nutrition office at the Dirceu Mendes Arcoverde integrated outpatient health department - at Getúlio Vargas Hospital, in Teresina, Piauí. For analysis and understanding of the problem, the method of qualitative inquiry, through semistructured interview, was used. The study made it possible to understand the food practices in their multidimensional: culture, tradition and collective and individual identity. These values, when not considered by professionals, make difficult the relation with the diabetics who will have a tendency to deny the problem, not joining satisfactorily to the therapy diet plan. Besides these cultural and affectionate values, also the economical limitations interfere in the adhesion of the patients to the dietetic treatment. The study detected the current and frequent use of the popular medicine in the attempt to cure or improve the disease. From the observations, we can contribute to vigilance of health, knowing subjective aspects of the reality with a regional focus and have subsidies for efficient educational and nutritional interventions in the promotion, prevention and education in health.
\end{abstract}

Key Words: Food practice, Diabetes Mellitus, Education in Health, Vigilance in Health 


\section{SUMÁRIO}

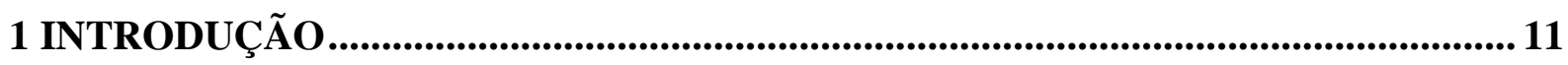

1.1 Panorama histórico e epidemiológico das doenças crônicas não transmissíveis no Brasil 11

1.2 A transição nutricional e a epidemiologia do Diabetes Mellitus ................................... 15

1.3 Antropologia e prática alimentar: um olhar indispensável ....................................... 20

1.4 Cultura alimentar no Brasil e no Piauí: panorama rápido ............................................ 24

$1.5 \mathrm{O}$ desafio da interdisciplinaridade na Vigilância em Saúde .......................................... 29

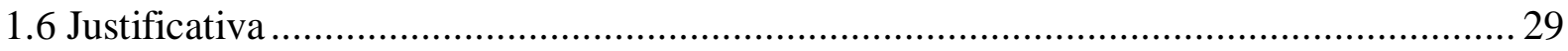

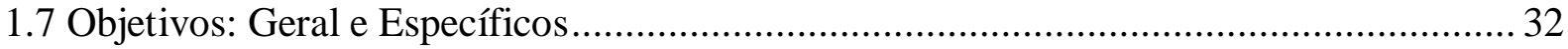

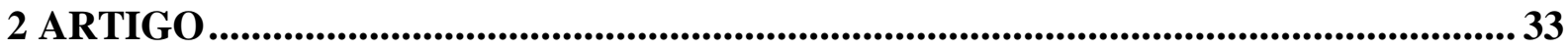

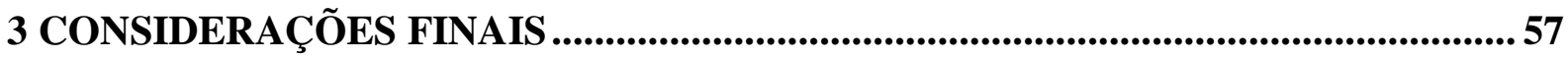

REFERÊNCIAS ........................................................................................................5 59

ANEXOS 


\section{LISTA DE TABELAS}

Tabela 1 Distribuição proporcional de YLL, YLD e DALY em ambos os sexos segundo causas. Brasil, 1998.

Tabela 2 Mortalidade proporcional por categorias de causas de óbitos. Brasil, 2002-2004 ... 14

Tabela 3 Mortalidade proporcional por categorias de causas de óbitos, com redistribuição das causas mal definidas, por região - Brasil, 2004 .............................................................. 14

Tabela 4 - Classificação etiológica do Diabetes Mellitus................................................... 18 
LISTA DE ABREVIATURAS

\author{
ADA - American Diabetes Association \\ DALY - Disability Adjusted Life of Years \\ DANT - Doenças e Agravos Não Transmissíveis \\ DCNT - Doenças Crônicas Não Transmissíveis \\ DM - Diabetes Mellitus \\ IMC - Índice de Massa Corporal \\ LDL - Low Dense Lipoprotein \\ OMS - Organização Mundial da Saúde \\ SBD - Sociedade Brasileira de Diabetes \\ SVS - Secretaria de Vigilância em Saúde \\ YLL - Years of Life Lost \\ YLD - Years Lived With Disability
}




\section{INTRODUÇÃO}

\subsection{Panorama histórico e epidemiológico das doenças crônicas não transmissíveis no} Brasil

O século XX foi marcado por importantes transformações no perfil epidemiológico no mundo. Nos países desenvolvidos, especialmente na Europa e América do Norte a transição epidemiológica ocorreu com o controle e erradicação de várias endemias e epidemias, devido ao investimento na melhoria das condições de vida da população. Estes investimentos consistiram em políticas públicas voltadas para educação, moradia, lazer, saneamento básico e aumento de renda da população. ${ }^{1}$

Segundo Possas ${ }^{2}$ a transição epidemiológica é consequiência de um processo histórico determinado por um conjunto de transformações econômicas, sociais e demográficas que acontece no interior das sociedades em determinado período de tempo.

A mudança dos padrões de morbidade, mortalidade e fecundidade - as duas últimas consideradas forças motrizes da dinâmica populacional - pode ser recortada em pelo menos quatro estágios de transição epidemiológica. ${ }^{3}$ Um primeiro estágio é marcado por elevados níveis de mortalidade e fecundidade, período de fome, predominância de doenças infecciosas e parasitárias e crescimento populacional lento. Um segundo estágio caracteriza-se pelo desaparecimento de pandemias, mortalidade em declínio e queda da fecundidade. Terceiro estágio: onde se observa a emergência das doenças provocadas pela atividade humana, com mortalidade e fecundidade baixas. Por último, com o aumento da expectativa de vida e a baixa fecundidade, resulta o envelhecimento populacional (com seus problemas sanitários específicos), novas doenças emergem, e, devido às condições urbanas e outros fatores, ressurgem doenças antes consideradas sob controle.

No Brasil - e nos países periféricos de modo geral - esse mesmo padrão pode ser observado, embora aqui as mudanças tenham se dado de forma mais acelerada que nos países ditos desenvolvidos. Um dos fatores de aceleração certamente foi a rápida urbanização de uma população antes majoritariamente rural. Decorreram significativas mudanças nas taxas de fecundidade e natalidade, redução da mortalidade infantil e aumento progressivo de expectativa de vida, com a consequente elevação do número de pessoas idosas. Assim, a pirâmide populacional brasileira atualmente apresenta um perfil aproximado do padrão 
vigente em países desenvolvidos, com uma maior participação de pessoas com mais de cinqüenta anos de idade. ${ }^{4,5,6,7,8,9}$

No Brasil, o controle relativo das doenças infecciosas e parasitárias e a mudança na estrutura populacional, dentre outros fatores, tiveram como consequiência um predomínio das Doenças Crônicas Não Transmissíveis (DCNT), alterando a maneira de adoecer e morrer da população. Historicamente, até a década de 70 predominavam as doenças infecciosas e parasitárias e, a partir daí, observamos um incremento da mortalidade por DCNT, particularmente as cardiovasculares, neoplasias e diabetes. ${ }^{\mathbf{4 , 5 , 6 , 7}}$

Por outro lado, em nosso país como um todo, essa transição epidemiológica não teve e não tem homogeneidade espacial ou temporal, apresentando características fortemente regionalizadas, em consonância com a diversidade sócio-econômica, o acesso a serviços de saúde, a velocidade da urbanização, a vigência de políticas públicas (particularmente as de saúde), os hábitos alimentares e acesso e uso de informações. ${ }^{7}$ Em algumas regiões é tão forte a presença das DCNTs como das doenças infecciosas e parasitárias. ${ }^{6}$ Este perfil epidemiológico complexo sugere a necessidade de políticas regionalizadas, de acordo com a diversidade dos lugares.

As doenças crônicas não transmissíveis (DCNT) se caracterizam por ter uma etiologia incerta, múltiplos fatores de risco, longos períodos de latência, curso prolongado e por estarem associadas a deficiências e incapacidades funcionais. ${ }^{10}$ Silva Junior ${ }^{\mathbf{1 1}}$ ainda acrescenta, "interação de fatores etiológicos conhecidos e desconhecidos, especificidade de causa desconhecida, ausência de participação ou participação duvidosa de microorganismos entre os determinantes; curso lento, prolongado e predominante; manifestações clínicas com períodos de remissão e exacerbação; lesões celulares irreversíveis e evolução para graus variados de incapacidade ou morte".

O grupo DCNT inclui as doenças cardíacas, as cérebro-vascular, os cânceres, o diabetes, a hipertensão arterial e as doenças auto-imunes.

Os estudos pioneiros sobre as DCNTs ocorreram nos países desenvolvidos, onde a transição epidemiológica primeiro se configurou em epidemias de obesidade, diabetes e outras doenças e agravos. Depois isso foi verificado nos países periféricos, como no Brasil, com o agravante das iniqüidades sociais e regionais. ${ }^{\mathbf{1 2}}$

A etiologia múltipla e complexa das DCNT compreende os macro-determinantes políticos, econômicos, sociais e ambientais, imbricados com fatores mais diretos, de ordem comportamental, como o tabagismo, o consumo excessivo de álcool, a alimentação inadequada, o baixo consumo de frutas e verduras, o consumo de gorduras saturadas e 
colesterol e o sedentarismo. ${ }^{14,15,16,17}$ Segundo estimativas da Organização Mundial de Saúde (OMS), sete fatores de risco para as DCNT fazem parte da lista dos quatorze fatores de maior relevância para a carga total de doença. ${ }^{\mathbf{1 8}}$

Os mecanismos biológicos e intermediários que podem influenciar o risco de doenças cardiovasculares são complexos e incluem, além da dieta com ingestão aumentada de níveis colesterol e gordura saturada - elevando lipídios sanguíneos e a pressão arterial -, a sensibilidade à insulina, a função endotelial, a tendência a trombose, o estresse oxidativo, a arritmia cardíaca e a adiposidade corporal. ${ }^{19}$

As doenças cardiovasculares são a primeira causa de morte no mundo, e os brasileiros convivem com esta realidade há pelo menos quatro décadas, acrescentando-se o aumento da mortalidade pelo diabetes e neoplasias, bem como a prevalência de múltiplos fatores de risco para as DCNT. ${ }^{12}$ Séries históricas da mortalidade no Brasil apontam que a proporção de mortes por DCNT nas capitais aumentou em mais de três vezes entre os 1930 e 1990.

O estudo de carga de doença no Brasil ${ }^{22}$ realizado pelo Ministério da Saúde (Tabela 1) utilizou como indicador o DALY (Disability Adjusted Life of Years: anos de vida perdidos ajustados por incapacidade), que mede simultaneamente o impacto da mortalidade e dos problemas de saúde que afetam a qualidade de vida dos indivíduos. As doenças não transmissíveis são responsáveis pelas maiores proporções de mortes prematuras (59\%), bem como por anos de vida vividos com incapacidade $(74,7 \%)$ e por anos de vida perdidos ajustados por incapacidade $(66,3 \%)$.

Segundo o Ministério da Saúde?, os dados apontam as DCNT como responsáveis por mais da metade dos óbitos ocorridos no Brasil, perfazendo 62,8\% do total no ano de 2004 (Tabela 2). As regiões sul e sudeste, seguida do nordeste, apresentaram as maiores taxas de mortalidade proporcional (Tabela 3). No geral, verifica-se que a proporção de óbitos por DCNT é maior nas faixas etárias mais elevadas, nos indivíduos com maior nível de escolaridade, nos indivíduos brancos e amarelos e nos municípios maiores e com melhores indicadores socioeconômicos. ${ }^{9}$ 
Tabela 1 Distribuição proporcional de YLL, YLD e DALY em ambos os sexos segundo causas. Brasil, 1998.

\begin{tabular}{lccc}
\hline \multicolumn{1}{c}{ Causas } & YLL (\%) & YLD (\%) & DALY (\%) \\
\hline Doenças infecciosas e parasitárias, & 26,0 & 19,8 & 23,5 \\
maternas parientais e nutricionais & 59,0 & 74,7 & 66,3 \\
Doenças não transmissíveis & 15,0 & 55,0 & 10,2 \\
Causas externas não intencionais e & & \\
intencionais &
\end{tabular}

Fonte: Schramm e colaboradores (2004).

a) YLL - Years of Life Lost - anos de vida perdidos.

b) YLD - Years Lived With Disability - anos de vida vividos com incapacidade.

c) DALY - Disability Adjusted Life of Years - anos de vida perdidos ajustados por incapacidade.

Tabela 2 Mortalidade proporcional por categorias de causas de óbitos. Brasil, 2002-2004

\begin{tabular}{|c|c|c|c|c|c|c|c|c|}
\hline Causas & 2002 & & 2003 & & 2004 & & Total & \\
\hline $\begin{array}{l}\text { I - Infecciosas, } \\
\text { materna, perinatais, } \\
\text { nutricionais }\end{array}$ & 123.014 & 12,5 & 1250417 & 12,5 & 126.985 & 12,4 & 375.416 & 12,5 \\
\hline Infecciosas & 80.883 & 8,2 & 83.809 & 8,4 & 86.573 & 8,5 & 251.265 & 8,4 \\
\hline Perinatais & 33.152 & 3,4 & 32.038 & 3,2 & 31.011 & 3,0 & 96.201 & 3,2 \\
\hline Nutricionais & 7.347 & 0,8 & 7.973 & 0,8 & 7.729 & 0,8 & 23.049 & 0,8 \\
\hline Maternas & 1.632 & 0,2 & 1.597 & 0,2 & 1.672 & 0,2 & 4.901 & 0,2 \\
\hline $\begin{array}{l}\text { II - Não } \\
\text { transmissíveis }\end{array}$ & 598.848 & 61,0 & 616.826 & 61,5 & 642.696 & 62,8 & 1.858 .370 & 61,8 \\
\hline Cardiovasculares & 267.339 & 27,2 & 274.065 & 27,3 & 285.543 & 27,9 & 826.947 & 27,5 \\
\hline $\begin{array}{l}\text { Outros não } \\
\text { transmissíveis }\end{array}$ & 201.603 & 20,5 & 208.070 & 20,8 & 216.352 & 21,1 & 626.025 & 20,8 \\
\hline Neoplasias malignas & 128.148 & 13,1 & 132.992 & 13,3 & 139.146 & 13,6 & 400.286 & 13,3 \\
\hline Outras neoplasias & 1.758 & 0,2 & 1.699 & 0,2 & 1.655 & 0,2 & 5.112 & 0,2 \\
\hline III - Externas & 115.046 & 11,7 & 115.556 & 11,5 & 115.873 & 11,3 & 346.475 & 11,5 \\
\hline Externa intencional & 58.076 & 5,9 & 59.490 & 5,9 & 57.016 & 5,6 & 174.582 & 5,8 \\
\hline $\begin{array}{l}\text { Externa não } \\
\text { intencional }\end{array}$ & 56.970 & 5,8 & 56.066 & 5,6 & 58.857 & 5,8 & 171.893 & 5,7 \\
\hline IV - Mal definidas & 144.756 & 14,8 & 144.534 & 14,4 & 138.519 & 13,5 & 427.809 & 14,2 \\
\hline $\begin{array}{l}\text { Mal definidas } \\
\text { sintomas }\end{array}$ & 133.561 & 13,6 & 133.433 & 13,3 & 126.922 & 12,4 & 393.916 & 13,1 \\
\hline Mal definida acidente & 11.195 & 1,1 & 11.101 & 1,1 & 11.597 & 1,1 & 33.893 & 1,1 \\
\hline Total & 981.664 & 100,0 & 1.002 .333 & 100,0 & 1.024 .073 & 100,0 & 3.008 .070 & 100,0 \\
\hline
\end{tabular}

Fonte: SIM/SVS/MS (2005).

Tabela 3 Mortalidade proporcional por categorias de causas de óbitos, com redistribuição das causas mal definidas, por região - Brasil, 2004.

\begin{tabular}{crrrrrr}
\hline Causas & \multicolumn{1}{c}{ CO } & \multicolumn{1}{c}{ NE } & \multicolumn{1}{c}{ NO } & \multicolumn{1}{c}{ SE } & \multicolumn{1}{c}{ S } & \multicolumn{1}{c}{ Total } \\
\hline \multirow{2}{*}{ Grupo I } & 8.700 & 35.200 & 10.479 & 61.730 & 15.891 & 132.000 \\
& 13,7 & 13,7 & 19,5 & 12,7 & 9,8 & 12,9 \\
\multirow{2}{*}{ Grupo II } & 44.091 & 190.558 & 35.060 & 367.133 & 127.760 & 764.602 \\
& 69,5 & 74,4 & 65,3 & 75,2 & 78,5 & 74,7 \\
\multirow{2}{*}{ Grupo III } & 10.658 & 30.338 & 8.144 & 59.178 & 19.152 & 127.470 \\
& 16,8 & 11,9 & 15,2 & 12,1 & 11,8 & 12,5 \\
\hline Total & 63.449 & 256.096 & 53.683 & 488.041 & 162.803 & 1.024 .072 \\
\hline
\end{tabular}

Fonte: SIM/SVS/MS (2005). 


\subsection{A transição nutricional e a epidemiologia do Diabetes Mellitus}

O termo transição é definido como passagem de um ponto, estado ou condição a outro. ${ }^{23}$ A transição nutricional brasileira se caracteriza por uma inversão dos padrões nutricionais - dos problemas da desnutrição aos problemas da obesidade - e aconteceu simultâneo às demais transformações aqui relatadas. Todas as transformações acontecidas no modo de vida das pessoas, na urbanização, na globalização, no acesso aos meios de comunicação, nos estilos de vida coletivos e individuais, no acesso e resolutividade dos serviços de saúde contribuíram para essas mudanças. ${ }^{\mathbf{8 , 1 2 , 1 3 , 2 4}}$

Na década de 1940, Josué de Castro, com sua Geografia da Fome, sistematiza informações sobre a situação alimentar e nutricional brasileira. Desde a segunda metade do século XIX haviam estudos publicados sobre a fome no Brasil, mas estavam centradas no saber médico e faziam parte de trabalhos das faculdades de medicina existentes na época. Assim, a obra de Josué de Castro introduz novos conceitos, definindo geograficamente as áreas de fome endêmicas e subnutrição, desenhando o mosaico alimentar brasileiro e o perfil da fome no país. ${ }^{25}$ Batista Filho ${ }^{8}$ considera que a obra citada faz referências aceitáveis para as necessidades nutricionais e o valor nutritivo dos alimentos, calculando boas estimativas para a adequação da dieta consumida; no entanto, a obra não apresentaria indicadores antropométricos, clínicos e bioquímicos que fossem devidamente padronizados para avaliação do estado nutricional em escala epidemiológica. Josué de Castro traça o mapa da fome no país, embora tenha feito generalizações para compor o primeiro cenário da problemática nutricional no Brasil.

No Brasil, desde os anos 1970 são realizados inquéritos nutricionais visando a orientação de políticas públicas. $\mathrm{O}$ estudo nacional de despesa familiar (ENDEFIBGE/INAN) foi o primeiro a ser realizado em todas as regiões brasileiras, entre os anos 1974-75, com domicílios representativos das diversas regiões: fizeram-se a pesagem direta dos alimentos consumidos diariamente por 55.000 famílias, por sete dias consecutivos. ${ }^{\mathbf{2 6}}$ Posteriormente a Pesquisa de Orçamento Familiar (POF), realizada nos anos de 1987-88 pelo IBGE e abrangendo as área metropolitanas, estimou o consumo alimentar a partir de gastos com alimentação. Em 1989 o mesmo instituto realizou a Pesquisa Nacional sobre Demografia Saúde e Nutrição (PNSN), medindo a antropometria (peso e estatura), saúde, renda, ocupação, habitação e participação em programas de alimentação. ${ }^{27}$ Mais recentemente, outros estudos do IBGE têm focado as diferenças regionais e urbano-rurais. ${ }^{\mathbf{2 8}}$ Todos estes estudos demonstraram que houve declínio na prevalência de desnutrição em crianças menores de 
cinco anos de idade e redução marcante nos valores de prevalência de deficiência estatural. Nos três primeiros grandes estudos, ENDEF, POF e PNSN foram observados diferenças significativas quando se comparava a desnutrição infantil em região rural da região urbana, sendo a primeira a mais acentuada. Os estudos de prevalência que contemplaram amostras das cinco macrorregiões do Brasil apontaram que nos últimos trinta anos, a prevalência de desnutrição em crianças menores declinou em cerca de $80 \%$. O ritmo de declínio da desnutrição se mostrou mais intenso nos períodos de 1973-74 e 1989. ${ }^{27}$

A transição nutricional no Brasil também é fortemente caracterizada por um aumento da prevalência de sobrepeso e obesidade, agravos com prevalência claramente epidêmica. ${ }^{28}$ Este mesmo fenômeno acontece em quase todos os países latino-americanos. ${ }^{29}$ Nesse contexto, a obesidade consolidou-se como agravo nutricional associado à alta incidência de doenças cardiovasculares, câncer e diabetes, interferindo no perfil de morbi-mortalidade das populações. $^{\mathbf{4 , 1 2}} \mathrm{O}$ mecanismo pelo quais a obesidade aumenta o risco de doenças cardiovasculares incluem a resistência à insulina, hipertensão arterial, hiperglicemia, aumento da fração LDL do colesterol e redução do HDL colesterol. ${ }^{\mathbf{1 6 , 2 0}}$

Nos últimos trinta anos, a evidência do dinamismo da obesidade é demonstrada por diferenças nítidas entre gêneros e por evolução temporal distinta entre as regiões. A partir do índice de massa corporal (IMC) maior que $30 \mathrm{~kg} / \mathrm{m} 2$, foi demonstrado que o problema aumentou em cinco vezes entre os homens adultos do Nordeste e três vezes no Sudeste, entre o período de 1974-75 e 2002-03. Entre as mulheres dessas regiões essa trajetória foi diferenciada, pois a obesidade duplicou no período de 1974-75 e 1989, passando então a declinar no período compreendido entre 1996 e 2002-03. No Nordeste o problema elevou-se de forma contínua até 1996, quando começa a ter um leve declínio no período de 2002 2003. ${ }^{28}$ Para o mesmo período, as observações indicam que a situação se tornou praticamente equivalente entre os dois sexos, na região Sudeste.

Estudos da alimentação dos brasileiros nos últimos anos demonstram que o consumo de carboidratos acompanha a variação de condições econômicas que caracterizam as regiões mais pobres, como o Norte e Nordeste ou o meio urbano/rural. ${ }^{7}$ Bem como o consumo elevado de sacarose nas regiões Nordeste, Sudeste e Centro-Oeste. ${ }^{28}$ O mesmo estudo aponta para aumento no consumo de carnes a partir de 1970, diminuição no consumo de leguminosas, raízes e tubérculos e aumento expressivo do consumo de produtos industrializados como biscoitos, açúcares e refrigerantes. É destacado também o baixo consumo de vegetais, frutas e verduras na dieta alimentar brasileira. ${ }^{28}$ Nesta direção, concluise que, com a mudança do padrão alimentar das famílias brasileiras, predominam os 
nutrientes ricos em gordura saturada e colesterol, carboidratos refinados e baixo consumo de fibras, vitaminas e minerais.

A preocupação com a alta prevalência da obesidade tem motivado a análise da sua multicausalidade, que é fortemente perpassada pelas diferenças sociais. ${ }^{\mathbf{1 3}}$ Nas classes pobres a obesidade é determinada pelo baixo consumo de proteínas de alto valor biológico e alto consumo de carboidratos e gorduras: essa prática, conhecida como farinização da dieta - dos bebês aos adultos -, corresponde ao consumo de alimentos de baixo custo. Nas classes abastadas, por sua vez, a obesidade é determinada pelo consumo excessivo de gorduras, carboidratos e proteínas de alto valor biológico. Associado às mudanças do padrão alimentar, estudos relacionam a obesidade e outras DCNT com o sedentarismo. Esse último seria condicionado pela mecanização das atividades do cotidiano, típica da sociedade urbana moderna. Assim, as análises temporais e espaciais do estado nutricional dos brasileiros, indicam inversão de tendências, com claro declínio da desnutrição e incremento da obesidade e neste cenário, importantes diferenças sociais e regionais.

"A conjugação dos diferentes estágios de morbidade revela a mudança no padrão epidemiológico em extremas desigualdades sociais e regionais expressas nos indicadores de saúde. Complexifica a realidade epidemiológica e, desta forma, confere a característica mais visível da chamada transição nutricional que é a complexidade".

(Escoda, 2002:223)

Segundo Batista Filho ${ }^{\mathbf{8}}$, a transição nutricional no Brasil, pode ser recortada em quatro etapas. Inicia com o desaparecimento do Kwashiorkor, seguida do desaparecimento do marasmo nutricional (ambos eram desnutrições gravíssimas associados a doenças infecciosas); surgimento do binômio sobrepeso/obesidade e uma quarta etapa de transição caracterizada por correção do déficit estatural da população brasileira, fenômeno que pode ser avaliado com seguimento numa perspectiva de tendência secular.

O Diabetes Mellitus compreende vários distúrbios do metabolismo que têm em comum a hiperglicemia. ${ }^{15}$ A hiperglicemia é resultado de defeitos na ação da insulina, na secreção de insulina pelas células beta das ilhotas de Langerhans, no pâncreas. Os primeiros relatos datam da era egípcia, onde no papiro de Erbs (século XV a.C.), já se descreviam sintomas que pareciam corresponder ao diabetes. Foi Aretaeus da Capadócia, na Grécia que em $70 \mathrm{dC}$, deu o nome de diabetes e fez a primeira descrição clinica: derretimento da carne e membros em urina. Galeno (131-201 dC) asseverou que o diabetes era uma fraqueza dos rins. Do século III dC ao VI dC, na China, Japão e India, nos livros sagrados, os Vedas, foi descrita 
a condição com poliúria e urina doce. Em 1674, o médico inglês Tomas Willis, atribuiu ao diabetes uma doença sanguínea como se a urina fosse embebida com mel e açúcar, diferenciando o diabetes mellitus do insípido. Em 1815, Chevreul estabeleceu a relação entre o açúcar do sangue e da uva ao qual Peligot deu o nome de glicose e foi dado o nome diabetes açucarada ou diabetes mellitus. As ilhotas do pâncreas, foram descritas por Langerhans em 1869 e a insulina (termo derivado do latim que significa ilha) foi identificada em 1921 por Frederick Banting e Charles Best, que injetaram extrato ativo de pâncreas em cão diabético, observando queda da glicose. No mesmo ano Collins injetou aquele extrato em um menino diabético, conseguindo controlar a glicemia. Na década de 50 e 60 surgiram as sulfoniluréias, primeiros hipoglicemiantes orais, e em 1960 obteve-se a síntese completa da insulina. Mais recentemente, através da modificação de um aminoácido da insulina de porco, conseguiu-se a insulina humana semi-sintética. Ainda mais recentemente, com o desenvolvimento da bioengenharia genética, obteve-se insulina fabricada por bactérias e leveduras - humana sintética, idêntica a produzida pelo homem. ${ }^{30,31}$

A classificação atual do diabetes mellitus é baseada na sua etiologia e não no tipo de tratamento. ${ }^{15}$ A classificação proposta pela Organização Mundial de Saúde (OMS) e pela Associação Americana de Diabetes (ADA) e Sociedade Brasileira de Diabetes pode ser visualizada na Tabela 4, acrescentando-se outras alterações, referidas como pré-diabetes: glicemia de jejum alterada e tolerância à glicose diminuída não são entendidas como entidades clínicas, mas como fatores de risco para o desenvolvimento do Diabetes Mellitus (DM) e de doenças cardiovasculares. ${ }^{15}$ O DM tipo 2 é a forma presente em mais de $90 \%$ dos casos e caracteriza-se por defeitos na ação e na secreção da insulina. A maioria dos indivíduos que manifestam o DM tipo 2 apresentam sobrepeso ou obesidade, idade maior que 40 anos e histórico familiar da doença. ${ }^{15}$

\section{Tabela 4 - Classificação etiológica do Diabetes Mellitus}

\begin{tabular}{|l|}
\hline DM1 \\
\hline Auto-imune \\
\hline Idiopático \\
\hline DM2 \\
\hline Outros tipos específicos de DM \\
\hline Diabetes Mellitus Gestacional \\
\hline Fonte: Sociedade Brasileira de Diabetes, 2006
\end{tabular}


A prevalência de DM tipo 2 constitui atualmente um grave problema de saúde pública. ${ }^{15,33,34,35}$ Os principais fatores que explicam o crescimento da prevalência de DM tipo 2 são o aumento da taxa de sobrepeso e obesidade ocorrida na ultima década, alterações de estilo de vida, e envelhecimento populacional., ${ }^{\mathbf{9 2 2 , 3 3 , 3 4}}$

O diabetes mellitus é uma das principais causas de morbi-mortalidade nas sociedades ocidentais. Sua prevalência aumenta com a idade, e é impactante na qualidade de vida dos indivíduos, além de sobrecarga de doença para o sistema público, acarretando custos

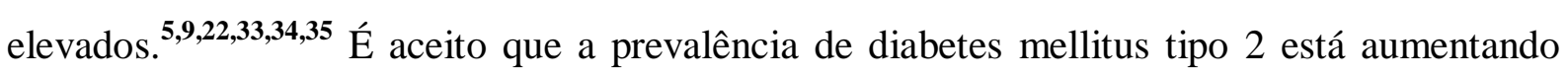
progressivamente e adquirindo características epidêmicas em vários países em fase de desenvolvimento. Autores também discutem a inexistência de um sistema de vigilância epidemiológica para doenças crônicas, em particular para o diabetes mellitus. ${ }^{\mathbf{1 2 , 3 4}}$ As informações sobre o diabetes e seus fatores de risco são pontuais, em inquéritos realizados esporadicamente e sem bases regulares. ${ }^{12,17,34}$

A Sociedade Brasileira de Diabetes (SBD) chama a atenção para a magnitude crescente do diabetes mundial: para o ano de 2002 era estimado um numero em torno de 173 milhões de pessoas, com projeção de se chegar em 2030 a 300 milhões de pessoas.

Analisando a importância do Diabetes como carga de doença, ou seja, o impacto da mortalidade e dos problemas de saúde que afetam a qualidade de vida dos seus portadores, através do Disability Adjusted Life of Years (DALY) - anos de vida perdidos ajustados por incapacidade - verifica-se que em 1999 o DM ocupava a oitava posição, sendo superado pelo grupo das doenças infecciosas e parasitárias, neuropsiquiátricas, cardiovasculares, respiratórias crônicas, do aparelho digestivo, neoplasias malignas e doenças musculoesqueléticas. Assim, nessa comparação, deve-se levar em conta que o diabetes, como única entidade, está sendo comparado com grupos de doenças e, mesmo assim, denota-se a sua importância.

No Brasil, um estudo multicêntrico com base populacional, realizado no período entre 1986- 1988 em nove capitais brasileiras, na população de 30 a 69 anos, encontrou uma prevalência de diabetes e tolerância à glicose diminuída de 7,6 e 7,8\%, respectivamente, segundo critérios da OMS. ${ }^{36} \mathrm{O}$ mesmo estudo ainda demonstrou um aumento na prevalência de diabetes à medida em que aumenta a idade com variação de 2,7\% para a faixa etária de 30-59 anos e de 17,4\% para a faixa etária de 60 a 69 anos. Em relação ao gênero, essa prevalência apresentou valores aproximados, nas mulheres $7,6 \%$ e nos homens foi de $7,4 \%$. Mantém-se também proporcional a prevalência do diabetes quando relacionada com a cor, os brancos perfazendo $7,7 \%$ e não-brancos, $7,3 \%$. O estudo multicêntrico demonstrou que quase 
metade dos pesquisados desconheciam sua doença $(46,5 \%){ }^{\mathbf{3 6}}$. O estudo ainda demonstrou que a história familiar de diabetes e a obesidade foram os principais fatores associados à maior prevalência de diabetes. Cidades da região sul e sudeste, consideradas de maior desenvolvimento econômico, apresentaram as maiores prevalências de diabetes mellitus e tolerância diminuída à glicose. ${ }^{36}$

Dados mais recentes apontam para taxas de prevalência mais elevadas; um estudo realizado em Ribeirão Preto, São Paulo, apontou uma prevalência de diabetes mellitus de $12,1 \%$ e de tolerância diminuída à glicose de $7,7 \%$ na população estudada. ${ }^{\mathbf{3 8}}$

Um desdobramento do estudo multicêntrico citado foi realizado em 1997 pela Escola Paulista de Medicina, consistindo de inquérito domiciliar em três áreas do distrito de São Paulo. O estudo caracterizou a prevalência de diabetes mellitus, segundo diferenciais social, de ocupação e de gênero. Os resultados apontaram para um aumento da prevalência de diabetes na população masculina, em função da busca ativa, invertendo a superioridade da concentração feminina observada para o diabetes pré-diagnosticado. Mas se desapareceu o diferencial por sexo, reafirma-se o gradiente social da prevalência. A busca ativa também demonstrou a importância da história familiar de diabetes para o pré-diagnóstico, evidenciando a potencialidade do diabetes submergida na população. ${ }^{38}$

Nos Indicadores e Dados Básicos para a Saúde fornecidos pela RIPSA-2005 (Rede Interagencial de Informações para a Saúde), do Ministério da Saúde, é dado destaque para a mortalidade por doenças crônicas. ${ }^{39}$ Entre as causas específicas, o diabetes apresenta uma mortalidade crescente desde 1980, para a população com 40 anos ou mais e em todas as regiões brasileiras. O número de óbitos informados no ano de 2003 mostra que a taxa de mortalidade por diabetes no Nordeste nesse ano para a população masculina foi de 16,5/100.000 habitantes e no Piauí essa taxa foi de 11,5/100.000 habitantes, enquanto que para a população feminina esses valores apresentavam-se maiores; o Nordeste, 23,1/100.000 e o Piauí, 20,4/100.000, habitantes, respectivamente.

\subsection{Antropologia e prática alimentar: um olhar indispensável}

A alimentação humana tem múltiplas dimensões. Diversos autores chamam atenção para o fato de que a alimentação, mais que um ato biológico, tem aspectos sociais e culturais. As escolhas alimentares são perpassadas por simbologias que atualizam a tradição em rituais e tabus. ${ }^{40,41,42,43,44}$ Assim, pela complexidade do tema e pela premente necessidade de se compreender todos esses aspectos que correlacionam a Antropologia e Saúde, 
especificamente a Antropologia e a alimentação muito se têm discutido a este respeito. A abordagem também se faz necessária ao se questionar sobre os problemas de saúde pública ${ }^{45}$ e o diálogo tem proporcionado vários enfoques, da fome à gastronomia. ${ }^{42}$

Nos anos 1960 a pluridisciplinaridade da Sociologia iniciou o diálogo entre as várias ciências. Na década seguinte, Edgar Morin oficializa o diálogo alimentação e antropologia, fundando a sociologia da alimentação com o seu o livro Lé Paradigme perdu: la nature humaine (O paradigma perdido: a natureza humana), onde é abordada a inter-relação de atividades essencialmente biológicas com a cultura do homem. ${ }^{46}$ A sistematização posterior da antropologia da alimentação deve-se a Claude Fischler, com trabalhos da década de 90, possibilitando condições de trabalho para a sociologia e as disciplinas vizinhas. A partir de então, fica estabelecido um diálogo franco entre as ciências nutricionais e sociológicas.

O comportamento alimentar é determinado por influências dinâmicas internas e externas à tradição cultural. ${ }^{40}$ Ao analisar as práticas alimentares fica evidente que o seu significado compreende percepções, experiências, significados e valores sobre a alimentação, e nesta direção aquelas práticas são constituintes da identidade social. ${ }^{\mathbf{4 0 , 4 6 , 4 7}}$

A cultura é entendida como um "sistema simbólico", um conjunto de mecanismos de controle, planos, receitas, regras e instruções que governam o comportamento humano, ${ }^{\mathbf{4 4}}$ dessa forma, o sistema cultural prescreve um caráter coletivo e não individual ou particular; dentro desse debate, é discutido a posição do sujeito na construção social, determinado pela sua vontade e interesses individuais que interagem e recriam o social, de forma dinâmica. ${ }^{45}$

Os hábitos alimentares podem ser compreendidos como integrantes de um sistema cultural, que é coletivo e repleto de símbolos, significados e classificações de modo que a prática alimentar está determinada pelas associações culturais que a sociedade lhe atribui. ${ }^{\mathbf{4 4}}$ Vários autores destacam que a cultura alimentar é constituída por hábitos alimentares que se mostram dinâmicos ao longo do tempo, não só no que diz respeito às raízes históricas, mas também ao cotidiano, que é composto pelo que é tradicional e pelo que se constitui como novos hábitos. ${ }^{\mathbf{4 4 , 4 7 , 4 8}}$ Os novos hábitos alimentares são um fenômeno evidente na transição nutricional, com várias influências, desde a globalização, industrialização e marketing de alimentos. ${ }^{40,48,49,50}$

Ao valorizar a dimensão cultural do comportamento alimentar, Freitas ${ }^{\mathbf{5 1}}$ reforça a visão de Bordieur, afirmando que, na comida, mesclam-se valores simbólicos antigos e modernos (inclusive características regionais) a padrões sócio-culturais das diversas instâncias do conhecimento: 
(...) a comida representa a manifestação da organização social, a chave simbólica dos costumes, o registro do modo de pensar a corporalidade do mundo, em qualquer que seja a sociedade.

(FREITAS, 1996:2)

Diversos autores que comungam a idéia de hábitos alimentares como prática social, e afirmam que esta compreensão permite contextualizá-los de forma mais ampla, inclusive em sua dimensão antropológica, representando um grande avanço em relação à visão estritamente fisiológica. ${ }^{40,42,48,50,52}$

Também a distribuição e o consumo de alimentos são determinados histórica e socialmente. A disponibilidade, o custo, a produção e a distribuição de alimentos condicionam seu consumo e integram sistemas normativos socialmente construídos por práticas alimentares distintas. ${ }^{53}$ Para Murrieta ${ }^{41}$, o processo das escolhas alimentares leva a esquemas exploratórios mais abrangentes:

"Defendo a hipótese de que o processo de escolhas alimentares são o resultado da interação dialética entre as estruturas habituais do cotidiano, os ciclos ecológicos dos recursos naturais, a dinâmica político-econômica dos mercados locais e regionais e as representações de classe e individuais". (Murrieta, 2001).

Os estudos das práticas alimentares têm possibilitado uma melhor compreensão sobre a intricada rede de associação entre alimentação e cultura, rede esta denominado espaço social alimentar, que corresponde à zona de liberdade que é dada aos homens por uma série de condicionantes materiais. É um conceito sociológico que direciona para a análise da alimentação de acordo com as influências sociais. Esse conceito, perpassando o desenho metodológico dos estudos, permite uma abordagem multidisciplinar. ${ }^{46}$

A dimensão do espaço social alimentar, o espaço do comestível, permite que o grupo faça suas escolhas dentre os produtos vegetais ou animais disponíveis. O sistema alimentar diz respeito ao conjunto de estruturas tecnológicas e sociais empregadas desde a coleta até a preparação dos alimentos. O espaço do culinário é marcado por uma linguagem que transmite as ações técnicas do ato de cozinhar, de práticas que definem simbolismos e rituais que participam da construção da identidade alimentar do grupo, de repartição sexual e social das atividades da cozinha. O espaço dos hábitos de consumo representa a estrutura do ato da alimentação: como comer, quando comer, onde comer. A temporalidade alimentar representa a forma de alimentação do homem determinada por estados fisiológicos da sua vida, tais 
como a alimentação na infância, no adulto e no idoso. Finalmente, o espaço de diferenciação social, que demarca fronteiras de identidade de grupos humanos.

Ao relacionarmos a antropologia e a história da alimentação, a contribuição dos dois campos permite observar rituais - reuniões sociais e festas - como espaços privilegiados para as construções identitárias, carregando traços culturais únicos. ${ }^{\mathbf{5 4}}$

O debate em torno do tema antropologia e alimentação é enriquecedor e denota a grande diversidade social e cultural do comportamento dos indivíduos de determinada sociedade relativo à comida. ${ }^{4 \mathbf{4 4 , 5 5 , 5 6}} \mathrm{A}$ comida e o ato de comer assumem papel central no aprendizado social por sua natureza vital e social, mesmo sendo rotineira. ${ }^{47}$ A fome está situada em uma esfera natural e universal e as práticas alimentares, que são também universais, não são naturais, pois se situam no campo da cultura, assim, diante desses dois pontos, é permitida a análise das diferentes naturezas do ato biológico da alimentação e da cultura. ${ }^{57}$

O primeiro elemento que distingue o homem civilizado dos bárbaros é a comensalidade. O homem civilizado come não somente por fome, mas transformou o comer em ocasião para a socialização, em um ato carregado de forte componente social e de grande poder de comunicação. A comensalidade é percebida como um elemento fundador da civilização humana. O convívio é a própria imagem da vida em comum (cum vivere). Os banquetes definem a identidade no núcleo familiar ou nos diversos grupos sociais. Estes verdadeiros rituais - que definem o lugar que cada um ocupa à mesa, os critérios de repartição e tipo de alimento servido a cada conviva - expressam a identidade social e representam hierarquias e relações de poder no interior do grupo. Assim, a mesa funciona como um agente de agregação e de unidade e também de separação e de marginalização. ${ }^{\mathbf{5 6}}$

$\mathrm{O}$ ato de comer, em cada grupo social, está em torno de sua comensalidade e à partir daí constroem-se regras que fazem parte de um sistema simbólico que correlaciona-se com outros sistemas.

$O$ ato de alimentar-se é sempre mediado por regras dietéticas, cujas origens e finalidades são múltiplas (...) são elaborados a partir de diversas formas de saber, como o conhecimento científico, o senso comum , as religiões.

(Romanelli, 2006).

À luz dessas afirmações, compreende-se as práticas alimentares como um processo construído pela experiência e aprendizado próprio de cada grupo social. ${ }^{48}$ Visualiza-se a dinâmica dessas práticas diante das transformações ocorridas nas últimas décadas em virtude 
da globalização, da massificação do gosto alimentar em resposta a produção industrial, interferindo diretamente na distribuição e consumo de alimentos, somando-se também a urbanização, estilo de vida das pessoas fazendo refeições fora de casa e o surgimento de fastfoods, principalmente nas regiões metropolitanas. ${ }^{\mathbf{4 0 , 4 4 , 4 9}}$

\subsection{Cultura alimentar no Brasil e no Piauí: panorama rápido}

As grandes navegações dos séculos XV e XVI assumem papel de extrema relevância, quando então os diversos continentes passaram a compartilhar suas culturas, dentre elas a cultura alimentar. ${ }^{42,58} \mathrm{O}$ Brasil é um dos grandes focos dessa mistura de culturas, exemplo de construção de cozinhas em um país colonizado através de grandes deslocamentos e das trocas de práticas alimentares. ${ }^{\mathbf{5 2}}$

Nos anos 1940 o médico, sociólogo e geógrafo Josué de Castro, com sua obra Geografia da Fome, descreve o consumo alimentar por regiões e se reporta especialmente em caracterizar o nordeste em situação de fome, traçando o mapa da fome no país. Sua obra foi um marco na problematização da fome e da desnutrição e seus determinantes socioeconômicos no Brasil. ${ }^{\mathbf{5 9}}$

Estudiosos brasileiros da alimentação, Luís da Câmara Cascudo, um folclorista, e o antropólogo Gilberto Freyre destacaram em suas obras a diversidade da cultura e das práticas alimentares no Brasil. Esses autores se debruçaram na história da alimentação no Brasil, detendo-se em separar regionalmente as práticas alimentares e a história da alimentação. Gilberto Freyre estuda a tradição alimentar das diversas regiões: colonial mineira (sopas de legumes, lombos de porco, doces de leite, requeijões), a colonial baiana (azeite de dendê, carurus, vatapás, mingaus e moquecas), a açoriana brasileira do Rio Grande do Sul e Santa Catarina (carne fresca e influências espanholas), a colonial paulista (influências indígenas assimiladas por bandeirantes), a do Pará e Amazonas (fortes influências ameríndias) e a colonial nordestina (zona açucareira, comidas de coco e quitutes de mandioca, doces de fruta, compota, sururu, lagosta e peixe). ${ }^{\mathbf{6 0}}$

Câmara Cascudo, por sua vez, autor da clássica obra, História da Alimentação, de 1967, abordou as contribuições dos três componentes principais - indígena, português e africano - fazendo referências e estabelecendo relações etnográficas, históricas e gastronômicas. A cultura indígena contribuiu para a base da alimentação, com mandioca, milho, batata e feijão, em preparações como pirões, papas e mingaus. Para o preparo dos alimentos os indígenas tinham predileção por assados, embora não utilizassem sal e óleo no 
preparo dos alimentos e também pelo consumo de frutas como o caju, abacaxi, goiaba, maracujá, mamão, maracujá e imbu. Também praticavam a caça e a pesca, tendo predileção pelo porco do mato. ${ }^{61}$ A farinha de mandioca continua com presença marcante no cardápio dos brasileiros, constituindo-se como um elemento fundamental no acompanhamento da dupla arroz com feijão, para todas as regiões e classes sociais, sendo mesmo considerado como um "prato nacional". ${ }^{42}$ Segundo ainda Câmara Cascudo, o binômio feijão com farinha era a base do sistema alimentar brasileiro no Século XVII, a alimentação dos escravos e dos soldados, sendo a farinha feita da mandioca ou do milho. Posteriormente, com a consolidação da produção de arroz, a farinha é deslocada do cardápio, porém, não se ausenta, permanecendo como um terceiro elemento no cardápio.

A contribuição dos africanos se destaca com o consumo da banana. Outros alimentos trazidos da África e adaptados ao Brasil foram o inhame, o quiabo, o açafrão, gergelim, melancia, jiló, dendê, pimenta africana e o único animal que vai participar da culinária brasileira, a galinha de Angola. ${ }^{61}$

Também os portugueses influenciaram fortemente a cozinha brasileira, inicialmente trazendo o sal para o Brasil, (sinalizamos que os indígenas não tinham hábitos de consumir o sal) o peixe salgado e também animais de corte, gado comestível: vacas, bois, ovelhas, cabras, galinhas, pombos, patos e gansos. A fonte de carboidratos na alimentação portuguesa trazida para o Brasil são os cereais: trigo, aveia, centeio e cevada e ainda o arroz, cuja origem é asiática, mas que foi trazido para o Brasil pelos portugueses. A cana-de-açúcar, outro produto também asiático trazido pelos portugueses, fez parte de um importante cenário econômico e cultural para o Brasil. ${ }^{\mathbf{5 8}}$ Inúmeras frutas e legumes também foram trazidas pelos portugueses: uva, figo, romã, laranja, limão, cidra, melão, pepino, nabo, mostarda, gengibre, couve, alface, coentro, salsa, cebolinha, alho, manjericão, cenoura, berinjela (esta última de origem árabe). Em relação às técnicas utilizadas para o preparo dos alimentos, citamos as frituras com o uso da banha - banha de porco e toucinho, a lingüiça e o presunto. Ainda, os ovos: para fritadas, bolos, mingaus, pirões, papas. As carnes mais comumente consumidas pelos portugueses: o porco e o carneiro. Em Portugal o consumo de galinha não era rotineiro: a canja de galinha era consumida por pessoas doentes e, nas festas, preparava-se a galinha assada.

Foi no nordeste onde mais se fundiram as três influências étnicas da cozinha brasileira, representadas pelos africanos que chegaram à Bahia trazendo uma culinária que incorporava oferendas ritualísticas aos seus orixás; da influência dos portugueses com sua culinária e também por trazerem a cana-de-açúcar, este produto, fazendo parte de muitas preparações culinárias que se difundiram no sertão, como a marmelada, além é claro, da contribuição dos 
povos indígenas com suas farinhas que compõem grande parte da alimentação de nordestinos. $^{\mathbf{6 1}}$

Estudos antropológicos que abordam a dimensão cultural das práticas alimentares no Brasil foram realizados nos anos de 1940-1960, com o objetivo de esclarecer as práticas, crenças, tabus e o saber sobre a produção e o consumo de alimentos dos diferentes grupos sociais, no meio urbano e rural. Na década de 1970 os estudos da alimentação no Brasil voltam-se para as questões das condições de vida e de saúde das camadas trabalhadoras; na antropologia os estudos preocupam-se com a explicação dos hábitos alimentares a partir da relação natureza e sociedade. ${ }^{\mathbf{6 2}}$

Quanto à culinária piauiense, segundo $\operatorname{Matos}^{63}$, ela não apresenta uma iguaria própria, exclusiva, embora a mesa seja bastante diversificada e adaptada aos produtos regionais. Esse autor faz uma viagem na culinária piauiense descrevendo as praticas alimentares da região, detalhando suas peculiaridades, sempre imbricadas com a história da colonização do Piauí. A culinária tem por base o boi e a farinha, produto da rústica mandioca que pode ser estocado, estando apto ao consumo durante os períodos de chuva e de estiagem. Afora africanos e portugueses, houve pouca influência direta de outros imigrantes, ao contrário do que aconteceu nas regiões sul e centro-oeste do país principalmente. A base da cozinha piauiense foi mistura e adaptação da culinária do nativo, do negro escravo africano, do português colonizador e em especial do mestiço paulista, pernambucano e baiano aventureiros. ${ }^{\mathbf{6 3}}$

No Piauí as festas populares e religiosas continuam fortemente marcadas pela tradição, especialmente as festas juninas, a semana santa, as festas de padroeiras, todas elas com culinária bastante diversificada. ${ }^{63}$ Os arraiais das festas juninas têm suas iguarias próprias: milho verde das vazantes (cozido ou assado), canjica com canela, pamonha enrolada na folha de milho, mugunzá com lasca de coco da praia, batata doce e jerimum assado na brasa, banana coruda (frita com açúcar e canela), roletes de cana caiana, além bolos e biscoitos (goma, milho, puba, bolo frito e rosca), cocada de coco e de jaca, frito de tripa de porco, paçoca com banana, lingüiça de porco temperada, e bebidas como o aluá e a cachaça.

A semana santa, festa religiosa com forte tradição no nordeste brasileiro, é marcada por ritos como a pratica do jejum, as imagens dos santos e espelhos cobertos, portas e janelas entreabertas e todas outras atividades da família e da comunidade voltadas para essa celebração. A prática alimentar era caracterizada pela proibição do consumo de carne vermelha, conforme as normas da igreja católica, sendo substituída por peixes, ovos, tubérculos, folhas e legumes. Nas famílias mais abastadas, por influencia do colonizador europeu, o consumo do bacalhau norueguês permaneceu. Na mesa dos piauienses a época da 
semana santa, os pratos mais comuns eram o feijão verde aferventado, o arroz com feijão (baião de dois), o ovo (cozido, frito ou mexido), a maxixada, o quibebe (que tem raízes africanas), macaxeira cozida ou frita, peixes regionais acompanhados de pirão com pimenta de cheiro, feijão do caldo grosso, com queijo coalho e frigideiras e ensopados de bacalhau.

A farinhada é uma atividade que preserva a tradição tupi-guarani de festa $e$ trabalho,geralmente com o caráter de mutirão. Ocorre nos meses de julho e agosto período em que a mandioca de ano e meio estava grossa e enxuta (seca). A casa de farinha, de aviamento ou casa de forno era o local onde se realizavam os trabalhos comunitários, com repartição das atividades entre homens e mulheres. Aos homens eram destinados trabalhos mais pesados, como arrancar a mandioca na roça, rodar a manivela do caititu, prensar a massa; às mulheres cabia descascar o tubérculo, cevar a mandioca e lavar a massa. Além da farinha e do polvilho (goma de mandioca) também se produzia o beiju puro ou coberto com o molho do leite do coco babaçu. Todas as noites o trabalho era substituído pela celebração e a alegria: as famílias levavam suas refeições de casa. Consumia-se cachaça para manter a conversa e a cantoria. O proprietário da casa de forno ficava controlando e observando a saída da farinha e da goma, para retirar a sua parte do arredamento da roça ou do serviço de aviamento. $^{63}$

As iguarias piauienses têm sua origem na adaptação nordestina da influencia dos colonizadores. O cuscuz, de origem portuguesa, mas, já da culinária dos mouros, tem amplo consumo pela população piauiense, confeccionado com massa de milho até os dias atuais, tendo-se ainda o cuscuz de arroz. A carne seca, de origem portuguesa, adaptou-se bem, visto o intenso sol do nordeste, preparada com as mantas cortadas mais finas e longamente expostas ao sol e salgadas, sendo utilizada para o preparo da paçoca, frito de carne, Maria Isabel (arroz com carne seca), ou para ser consumida trinchada com ovos ou cuscuz no café da manhã, ou ainda como refeição principal, com arroz branco e farinha. A carne de sol, por sua vez, é uma mais atual e urbana, com suas mantas ou peças mais grossas, menos salgadas e com menos exposição ao sol (mantém-se pouco desidratada).

O beiju, uma iguaria indígena, é servido rusticamente nas farinhadas, mas nas casas ele é preparado bem fino e consumido com a tradicional manteiga de garrafa, também conhecida como manteiga de nata. Assim como o beiju, a paçoca já fazia parte da culinária indígena, que pilavam o peixe frito com farinha de mandioca: a adaptação consistiu em substituir o peixe pela carne seca. No Piauí, há registros de pilões confeccionados do âmago do pau d'arco ou do jatobá, nas antigas fazendas de gado. Em alguns lugares, nas datas festivas, a paçoca era mais bem pilada em pilões naturais de pedra (bolhas vulcânicas em 
pedras cindidas), o que exigia um esforço maior de deslocamento até onde estes se encontravam.

Outras preparações feitas com vísceras de animais domésticos são ingredientes básicos de muitos pratos da cozinha local. O consumo de vísceras origina-se dos portugueses, mas também é condicionado pela localização geográfica do Estado do Piauí, longe do mar e tendo a pecuária como principal atividade econômica. Outros preparos de vísceras ainda bastante consumidas são a panelada, o sarapatel e a tripa de porco. Não se pode esquecer a mão-devaca, também conhecida como chambaril. Todos estes preparos são especialmente apreciados, e não só pela sua tradição, mas também pelo seu baixo custo, tornando-os acessíveis à maioria da população.

O perfil do consumo alimentar no Piauí mostra uma culinária fortemente caracterizada por preparações de alto valor calórico, composta de carboidratos complexos e rica em gorduras saturadas. A maior parte das gorduras saturadas é de origem animal, e vêm na panelada, mão-de-vaca, sarapatel, tripa de porco, carne de sol e também de outras preparações típicas. Doces caseiros: casca de limão, batata doce, coco com batata, doce de leite, buriti, doce de buriti e rapadura. Acresce que, em algumas preparações como arroz e carnes e suas misturas, e também bolos fritos, é utilizado o óleo de coco de babaçu, única fonte vegetal de gordura saturada, por ser facilmente encontrado na região, ter boa aceitação na sua palatabilidade, além de baixo custo e com uso já arraigado pela população.

Um fato importante a ser considerado é que a tradição culinária no Piauí e em Teresina, permanece praticamente a mesma até os dias atuais. Isto pode ser reflexo da tímida atividade turística no Estado, o que faz com que, diferente de outros lugares, sofra pouca influencia de outras culturas alimentares contemporâneas. Certamente que na capital, Teresina, podemos observar mudanças nas práticas alimentares em função do maior contato com a globalização alimentar, e onde há uma classe média com maior poder aquisitivo, o que naturalmente se reflete no seu cotidiano. Ainda assim, segundo Damásio ${ }^{64}$, alguns restaurantes e bares da cidade, remetem os seus habitantes e visitantes a permanecerem ou conhecerem a culinária piauiense. $\mathrm{E}$ isso fortalece os brios dos piauienses, o orgulho do pertencimento à terra:

“(...) é feliz quem come aqui! (...) as melhores cozinhas da nossa cidade: panelada com arroz branco do Restaurante Gurguéia no inicio da Barão , mão-de-vaca no bar do baxim, próximo a entrada do João Emilio Falcão (...) frito de tripa de bode no bar do João e pra curar a ressaca o melhor da cidade e o caldo de carne do Bar do Ceará, xis com o Mercado do Mafuá"

(Damasio, 2008) 


\subsection{O desafio da interdisciplinaridade na Vigilância em Saúde}

A transição epidemiológica e nutricional ocorrida no país nas ultimas décadas tem modificado o perfil da morbi-mortalidade e assim, embora as mudanças acontecidas não tenham ocorrido de forma homogênea, o padrão de ocorrência das doenças tem sido colocado como mais um desafio na tomada de decisão dos gestores do setor de saúde. ${ }^{6}$

Os problemas alimentares são bons indicadores de vida da população, e as práticas alimentares podem se apresentar como um fator de risco ou de proteção à saúde. A vigilância epidemiológica "é o conjunto de informações que permite reunir a informação indispensável para conhecer o comportamento ou história natural das doenças, bem como detectar ou prever alterações de seus fatores condicionantes, com o fim de recomendar oportunamente, sobre bases firmes, as medidas indicadas e eficientes que levem à prevenção e ao controle de determinada doença". ${ }^{65}$ Assim, a secretaria de vigilância em saúde, do Ministério da Saúde, tem o papel importante de implementar políticas públicas voltadas para a prevenção e controle de doenças crônicas não transmissíveis, bem como a promoção da saúde

A Vigilância em Saúde preocupa-se em monitorar as Doenças Crônicas Não Transmissíveis através de seus indicadores e também o monitoramento de fatores de risco para DANT, que devem contemplar a diversidade de uma realidade local.

\subsection{Justificativa}

Desde que iniciei a prática profissional de nutrição, mais precisamente em atendimento ambulatorial, emergiram reflexões e preocupações com meu exercício profissional em relação a dificuldades de adesão às orientações nutricionais prescritas para pessoas com diabetes. Essas reflexões foram se tornando mais intensas quando mais recentemente iniciei a docência em nível superior, também na área de nutrição clínica, aqui, enquanto professor, com responsabilidade de levar ao educando reflexões e posturas adequadas frente às questões de nutrição.

Percebeu-se que dificuldades de adesão às orientações nutricionais não diz respeito apenas a pessoas com diabetes, mas também a compreensão por parte dos profissionais de saúde dos problemas que essas pessoas enfrentam para fazerem mudanças de suas práticas alimentares. Ao longo do tempo, as observações nessas pessoas nos inquietaram, visto que a prática alimentar não deve ser vista de maneira isolada, apenas com um enfoque biológico ou fisiológico, mas com um olhar mais abrangente por tratar-se de práticas sociais onde se 
encontram embutidos valores culturais e comportamentais, poder aquisitivo para compra de alimentos, hábitos alimentares construídos desde a infância, hábitos alimentares regionais, globalização, influências da mídia, enfim, várias dimensões que a realidade nos mostra.

Refletir sobre a prática alimentar nos remete a pensar nos valores incorporados a essas práticas, que têm ampla dimensão. As políticas públicas em saúde voltadas para a vigilância em saúde, a educação em saúde e políticas de alimentação e nutrição têm considerado que é necessário um processo de reformulação e de novas abordagens em se tratando de controle, prevenção e promoção da saúde.

Nessa perspectiva, o estudo das praticas alimentares, com olhar interdisciplinar, entre Vigilância em Saúde, Nutrição e Antropologia, tem expressado um sentido de transformação da realidade da saúde, portanto, um projeto educativo que se supõe nessa direção deve prever práticas de Vigilância em Saúde eficazes. Assim, o estudo assume relevância para modificações de uma realidade, o que estimulará os gestores públicos na tomada de decisões eficazes que privilegie políticas de saúde, de comunicação em saúde e educação em saúde e que também fortaleça a Vigilância em Saúde nas Doenças Crônicas Não Transmissíveis, mais particularmente, no Diabetes Mellitus. É no interior desses aspectos que se embasa teoricamente a investigação e que surgem as idéias constitutivas de definição de nosso objeto de estudo.

\section{Delimitação do objeto: uma visão problematizadora}

Com o ingresso no curso de mestrado do Programa de Pós Graduação do Mestrado Profissional em Saúde Pública, com área de concentração em Vigilância em Saúde, fomos submetidos a intenso processo de ampliação e renovação de aprendizados. Assim, as leituras realizadas, as discussões empreendidas com o professor orientador e o desenvolver das disciplinas cursadas ampliaram os horizontes e foram fundamentais para que o projeto de pesquisa deixasse sua condição de proposta e dentro desse processo evolutivo de maturação científica, atingisse o corpo da presente dissertação.

O confronto do material empírico da pesquisa com o referencial teórico sobre a Vigilância em Saúde, Nutrição e Antropologia, levou a caminhos até então desconhecidos e considerados fundamentais no processo de formação da pesquisadora, não somente por uma série de transformações na forma de pensar e agir em relação a pesquisa, como também no âmbito profissional, tornando mais freqüente e frutífera a reflexão da prática profissional. Um 
olhar mais atento e sagaz no que diz respeito à postura do profissional de Nutrição, no diálogo com os clientes atendidos no consultório e nas prescrições das orientações nutricionais.

A preocupação com o acompanhamento nutricional e a educação em saúde nos remete à prática profissional desenvolvida mais especificamente por nutricionistas. A complexidade do entendimento desse processo nos impulsiona a delinear o seguinte objeto de estudo: a prática alimentar.

As práticas alimentares estão inseridas nas dimensões simbólicas da vida social, envolvidas nos mais diversos significados, desde o âmbito cultural até as experiências pessoais. Nessa direção, considerando que deve ser superada a fronteira que separa a ciência nutricional - de orientação essencialmente biomédica - das ciências sociais e humanas, ${ }^{\mathbf{6}}$ buscamos associar a questão da natureza e da diversidade que abrange as práticas alimentares com a experiência que as pessoas têm com a própria doença. Segundo alguns autores, as representações sociais, constituem um campo fértil a ser estudado explicando a complexidade que as envolve e, por outro lado, o campo da educação em saúde com suas práticas teóricas e metodológicas também em crescente reflexão. ${ }^{67,68}$

O diabetes é um importante problema de saúde pública, cujas conseqüências a médio e longo prazo, são deletérias e irreversíveis para seus portadores. Temos na alimentação e nutrição um alicerce de fundamental importância para o controle dessa enfermidade. Modificações de estilo de vida, tais como, alimentação saudável, prática de atividade física, abandono do tabagismo, são fatores que podem contribuir de maneira positiva.

Um dos pressupostos do estudo é que os profissionais de saúde e nutricionistas, quase sempre, dispõem apenas do seu conhecimento técnico no seu diálogo com pessoas portadoras de diabetes. Geralmente desconhecem que as pessoas possuem suas próprias percepções sobre a doença, que são construídas a partir da experiência com a enfermidade e pela representação social da doença. Assim, imbricam-se valores, práticas, conhecimentos e saberes. Nesse sentido, o desenvolvimento desta proposta de investigação demandou como eixos direcionadores, as seguintes questões: a) De que forma as práticas alimentares dificultam a adesão às dietas e orientações nutricionais prescritas para as pessoas com Diabetes Mellitus atendidas no Ambulatório do Hospital Getúlio Vargas?; b) Quais as práticas alimentares dessas pessoas no seu cotidiano? Como se caracteriza as percepções sobre a doença e a dieta das pessoas com Diabetes Mellitus? 


\subsection{Objetivos: Geral e Específicos}

\section{Objetivo Geral}

Caracterizar as dificuldades para a mudança de práticas alimentares de pessoas com Diabetes Mellitus tipo 2 atendidas no consultório de Nutrição do Ambulatório Dirceu Mendes Arcoverde do Hospital Getúlio Vargas em Teresina, Piauí.

\section{Objetivos Específicos}

a) identificar as práticas alimentares de pessoas com Diabetes;

b) conhecer a dimensão valorativa das práticas alimentares de pessoas com diabetes dentro da realidade das classes populares residentes no município de Teresina.

c) descrever as percepções sobre alimentação das pessoas com diabetes.

Nessa direção, consideramos importante que nossa investigação possa contribuir para as práticas de vigilância em saúde e ações de educação e comunicação em saúde. 
2 ARTIGO 


\title{
PRÁTICA ALIMENTAR E DIABETES: DESAFIOS PARA A VIGILÂNCIA EM SAÚDE
}

\author{
Andréa Fernanda Lopes dos Santos \\ José Wellington Gomes Araújo
}

\begin{abstract}
RESUMO
Importantes mudanças marcaram o perfil epidemiológico do Brasil nas últimas décadas, principalmente a diminuição das doenças infecciosas e parasitárias e o aumento das doenças crônicas não transmissíveis. Dentre estas o Diabetes Mellitus que, com uma prevalência alta e ascendente, limita a qualidade de vida de milhões de brasileiros, além de contribuir fortemente para o incremento das taxas de mortalidade, seja como causa básica ou associada. O Diabetes Mellitus configura-se, portanto, como um problema prioritário para a saúde pública do país.

Para os profissionais que lidam com este problema é notória a dificuldade que as pessoas têm para mudar os seus hábitos alimentares, orientação geralmente requerida na terapia antidiabética. E assim o presente estudo tem por objetivo investigar as dificuldades de mudanças de praticas alimentares de pessoas com Diabetes Mellitus, buscando compreender suas percepções, experiências e valores associados à alimentação. Com os resultados espera-se poder subsidiar uma prática profissional dialogada e humanizada, de acordo com a atual política de Vigilância da Saúde. O estudo considera a diversidade cultural da alimentação e as realidades locais, esperando assim contribuir para uma prevenção e controle mais efetivos da doença. O universo estudado foram pessoas com Diabetes Mellitus tipo 2, atendidas no consultório de nutrição do ambulatório integrado de saúde Dirceu Mendes Arcoverde Hospital Getulio Vargas, em Teresina, Piauí. Para análise e compreensão do problema, foi utilizado o método da pesquisa qualitativa, através de entrevista semi-estruturada. O estudo possibilitou compreender as práticas alimentares em sua multidimensionalidade: cultura, tradição e identidade coletiva e individual. Estas valorações, quando não consideradas pelos profissionais, dificultam a relação com as pessoas portadoras da doença, que tenderão a negar o problema, não aderindo satisfatoriamente ao plano dieto-terápico. Além destes valores culturais e afetivos, também as limitações econômicos interferem na adesão das pessoas ao tratamento dietético. O estudo detectou o uso corrente e frequente da medicina popular na tentativa de cura ou melhora da doença. A partir das constatações, podemos contribuir para a Vigilância em Saúde, conhecendo aspectos subjetivos da realidade com foco regionalizado e ter subsídios para intervenções educativas e nutricionais eficazes na promoção, prevenção e educação em saúde.
\end{abstract}

Palavras-chave: Prática alimentar, Diabetes Mellitus, Educação em Saúde, Vigilância em Saúde 


\begin{abstract}
Important changes marked the epidemiological profile of Brazil in the last decades, principally the decrease of the infectious and parasitic diseases and the increase of the non transmittable chronic diseases. Among these, besides contributing strongly to the growth of the taxes of mortality, Diabetes Mellitus that, with a high and rising predominance, limits the quality of life of million Brazilians, being a basic or an associate cause. Diabetes Mellitus is shaped, so, like a priority problem for the public health of the country.

For the professionals who deal with this problem, it is obvious the difficulty individuals have to change their food habits, direction generally applied in the anti-diabetic therapy. And so the present study aims to investigate the difficulties in changing food practices of patients with Diabetes Mellitus, trying to understand their perceptions, experiences and values associated to the food. It is expected from the results to be able to subsidize a professional dialogued and humanized practice, in accordance with the current policy of Drug and Food Association. The study considers the cultural diversity of the food and the local reality, hoping to contribute to a more effective prevention and control of the disease. The subjects studied were patients with Diabetes Mellitus type 2, assisted in the nutrition office at the Dirceu Mendes Arcoverde integrated outpatient health department - at Getúlio Vargas Hospital, in Teresina, Piauí. For analysis and understanding of the problem, the method of qualitative inquiry, through semistructured interview, was used. The study made it possible to understand the food practices in their multidimensional: culture, tradition and collective and individual identity. These values, when not considered by professionals, make difficult the relation with the diabetics who will have a tendency to deny the problem, not joining satisfactorily to the therapy diet plan. Besides these cultural and affectionate values, also the economical limitations interfere in the adhesion of the patients to the dietetic treatment. The study detected the current and frequent use of the popular medicine in the attempt to cure or improve the disease. From the observations, we can contribute to vigilance of health, knowing subjective aspects of the reality with a regional focus and have subsidies for efficient educational and nutritional interventions in the promotion, prevention and education in health.
\end{abstract}

Key Words: Food practice, Diabetes Mellitus, Education in Health, Vigilance of Health 


\section{INTRODUÇÃO}

Importantes transformações marcaram o perfil epidemiológico do Brasil nas últimas décadas. De um quadro caracterizado por altas taxas de morbidade e mortalidade por doenças infecciosas e parasitárias transitou-se, em um período de tempo relativamente curto, para um predomínio das Doenças Crônicas Não Transmissíveis, disso decorrendo alterações na maneira de adoecer e morrer da população. ${ }^{\mathbf{1 , 2 , 3 , 4}}$ No Brasil como um todo essa transição epidemiológica não é homogênea, o que pode ser explicado pelas diferenças regionais quanto à situação socioeconômica, de acesso a serviços de saúde, diversidade cultural, velocidade de urbanização, acesso e uso de informações, mudanças de estilo de vida. ${ }^{\mathbf{3 , 4}, 5}$ Historicamente, a mudança lenta do perfil epidemiológico acelera-se a partir dos anos 1970, quando se observa um incremento acentuado da mortalidade por doenças cardiovasculares, neoplasias e diabetes, principalmente. ${ }^{\mathbf{3 , 5 , 6}}$

As Doenças Crônicas Não Transmissíveis (DCNT) se caracterizam por ter uma etiologia incerta, múltiplos fatores de risco, longos períodos de latência e curso prolongado, do que decorrem deficiências e incapacidades funcionais que limitam enormemente a qualidade de vida das pessoas afetadas. ${ }^{7}$ A complexidade etiológica das DCNT implica que elas são condicionadas pelos aspectos sociais, culturais, políticos e ambientais; e, de forma mais direta, por fatores de risco comportamentais e atitudinais que se imbricam de forma sinérgica: tabagismo, consumo excessivo de álcool, alimentação inadequada, dislipidemias, baixo consumo de frutas e verduras, consumo elevado de colesterol e gordura saturada e sedentarismo. ${ }^{\mathbf{8 , 9 , 1 0}}$

O Estudo Multicêntrico de prevalência de Diabetes Mellitus realizado em nove capitais brasileiras em 1986-1988, na população de 30 a 69 anos, encontrou uma prevalência de 7,6\%, segundo os critérios de diagnóstico da OMS. ${ }^{\mathbf{1 1}}$ Dados mais recentes apontam para taxas de prevalência mais elevadas. Um estudo realizado em Ribeirão Preto, São Paulo, apontou uma prevalência de $12,1 \%$ na população estudada com a mesma faixa etária. ${ }^{\mathbf{1 2}}$ Segundo a Sociedade Brasileira de Diabetes, é estimado que no Brasil em 2005, existam em torno de oito milhões de indivíduos com DM. ${ }^{8}$

A maioria dos fatores de risco para Doenças Cardiovasculares são os mesmos para o Diabetes. A conjugação de fatores como sedentarismo, dieta inadequada e obesidade contribuem para o aumento da prevalência dessas doenças. No monitoramento, os fatores de risco passíveis de controle são de ordem comportamental (que também são os que apresentam associações mais consistentes com as DCNT), exigindo estratégias de intervenção bem 
elaboradas, inovadores e convincentes, para que sejam bem sucedidas. ${ }^{4}$ Dentre os agravos fortemente associados ao padrão alimentar - que pode funcionar como fator de risco ou de proteção - destacam-se o diabetes, a obesidade, a hipertensão arterial e as dislipidemias, que por isso necessitam de um acompanhamento clínico-nutricional permanente. Por sua vez, a síndrome metabólica é bem um caso em que se imbricam fatores comuns tanto às doenças cardiovasculares quanto ao diabetes: obesidade central, resistência a insulina, hipertensão arterial e hipertrigliceridemia. Esta síndrome aumenta a mortalidade geral em 1,5 vezes e a mortalidade cardiovascular em cerca de 2,5 vezes. $^{\mathbf{1 3}}$

Os problemas alimentares e nutricionais têm sido amplamente discutidos entre os pesquisadores desse campo. ${ }^{6} \mathrm{O}$ aumento das taxas de sobrepeso e obesidade associado aos estilos de vida e ao envelhecimento populacional são os principais fatores que explicam o crescimento da prevalência de diabetes tipo $2^{\mathbf{5 , 1 4 , 1 5 , 1 6}}$ A orientação nutricional e o estabelecimento de dieta para o controle metabólico de pacientes com Diabetes Mellitus associados a mudanças no estilo de vida, incluindo a atividade física, são considerados terapias fundamentais. No plano alimentar, deve-se levar em consideração os hábitos alimentares dos indivíduos, suas condições socioeconômicas e acesso aos alimentos.

Conforme já apontado, o controle dos fatores de risco relaciona-se principalmente com mudanças nos hábitos alimentares e com a prática de atividades físicas. Mas as mudanças esperadas não são fáceis de serem realizadas, pois envolvem valores arraigados na cultura, nas tradições regionais e no espaço social alimentar do homem. ${ }^{17,18}$ A alimentação humana tem múltiplas dimensões. Diversos autores chamam atenção para o fato de que a alimentação não se limita a um ato que satisfaz necessidades biológicas: mais que isso representa valores sociais e culturais, por sua vez envoltos em aspectos simbólicos que materializam a tradição em ritos e tabus. ${ }^{19,20,21,22}$ Portanto, a visão antropológica da alimentação também se faz necessária quando se aborda a questão na área da saúde pública ${ }^{23}$, e esse diálogo tem proporcionado vários enfoques, da fome à gastronomia. ${ }^{21} \mathrm{O}$ debate em torno do tema antropologia e alimentação enriquece a compreensão da forma como os aspectos sociais e culturais condicionam o comportamento dos indivíduos de determinada sociedade relativo aos seus hábitos alimentares. ${ }^{18,24,25,27}$

As práticas alimentares também têm sido investigadas sob outros vários ângulos, como a modernização, a intensificação do comercio e a globalização alimentar. $O$ interesse nestes aspectos resulta do fato que, mantendo um forte dinamismo ao longo do tempo, têm desempenhado um importante papel na construção de novos hábitos alimentares. ${ }^{19}$ 
No Brasil, a história da alimentação corresponde à sua história social, econômica e cultural. ${ }^{\mathbf{2 6}}$ Câmara Cascudo, Gilberto Freire e Josué de Castro destacaram em suas obras a diversidade da cultura e de práticas alimentares, compondo uma verdadeira sociologia e antropologia da alimentação no Brasil. Ressalta-se que a obra de Josué de Castro, Geografia da Fome, caracteriza o Brasil por regiões e consumo alimentar, enfocando especialmente o Nordeste em situação de fome. Gilberto Freire e Câmara Cascudo, em suas obras, especificam as tradições brasileiras por região e as influencias dos três componentes - indígena, português e africano - quanto a origem da dieta brasileira, fazendo referências históricas, gastronômicas e etnográficas. ${ }^{\mathbf{2 6}}$

\section{A TESSITURA METODOLÓGICA}

Para o controle de agravos à saúde da população fazem-se necessários indicadores quantitativos que orientem as políticas públicas e as estratégias de abordagem: este é o campo da epidemiologia na saúde coletiva. Por outro lado, quando este controle depende da mudança de hábitos como os alimentares, faz-se necessário também a compreensão dos valores envolvidos com estes hábitos. Procurar entender as práticas alimentares de pessoas com diabetes a partir de uma linha sócio-antropológica nos levou a uma investigação de natureza qualitativa. Realizou-se um estudo descritivo cujo objetivo foi investigar as dificuldades para a mudança das práticas alimentares de pessoas com Diabetes Mellitus atendidas no consultório de Nutrição de um Ambulatório de alta complexidade no município de Teresina. A metodologia qualitativa explora a experiência das pessoas em sua vida cotidiana, buscando compreender questões da sua própria realidade, incluindo fatos, fenômenos e situações, o que, a rigor, não pode ser quantificado. ${ }^{28}$

O cenário de investigação foi o Hospital Getúlio Vargas, da rede SUS estadual. É um hospital de ensino, de nível terciário e referência regional, localizado em Teresina, Piauí. O ambulatório deste hospital recebe grande afluxo de pessoas de bairros periféricos de Teresina, de cidades do interior e de estados vizinhos. Os sujeitos do estudo foram pessoas com diagnóstico de Diabetes Mellitus tipo 2, atendidos no consultório de Nutrição daquele Ambulatório. Os sujeitos, em sua maioria, foram encaminhados ao profissional de nutrição (responsável pela pesquisa) por médicos (endocrinologista, cirurgião geral, oftalmologista) ou outros profissionais (fisioterapeutas) do mesmo hospital, bem como de outros serviços (Estratégia Saúde da Família). Os critérios de inclusão para o estudo referiam-se a pessoas com diabetes tipo 2, entre 18 e 60 anos de idade e residentes em Teresina. Exclusos os não 
residentes em Teresina, pessoas de grupos vulneráveis (população carcerária, indígenas, pessoas com transtornos psiquiátricos) e gestantes ou nutrizes com diabetes gestacional.

O instrumento de coleta de dados foi um roteiro para entrevista semi-estruturada, aplicado após previa autorização dos sujeitos pesquisados. Esse tipo de procedimento permite que o entrevistado possa discorrer com maior liberdade sobre o tema proposto, sem respostas pré-definidas pelo pesquisador. ${ }^{29}$ Realizadas as entrevistas, seus resultados foram examinados com a referência teórica da análise de conteúdo, metodologia proposta por $\operatorname{Bardin}^{\mathbf{3 0}}$ que tem como pressuposto uma concepção crítica e dinâmica da linguagem, enquanto construção real de toda a sociedade e como expressão da existência humana, que em diferentes momentos desenvolve representações sociais no dinamismo interacional que se estabelece em linguagem, pensamento e ação. ${ }^{31}$ Em outras palavras, os valores supostamente associados às práticas alimentares e que são objeto desse estudo, têm a sua expressão na linguagem através de representações socialmente aceitas por determinado grupo. Isso significa também que, por não pertencerem a cada indivíduo separadamente, essas representações são em número relativamente limitado. Por sua vez isso implica que, para os procedimentos ditos qualitativos, uma amostra não tem o caráter de aleatoriedade ou representação estatística: um pequeno número de pessoas pode ser suficiente quando o tema está bem recortado e os critérios de inclusão e exclusão de sujeitos estão coerentes com os objetivos e métodos da pesquisa.

$\mathrm{Na}$ análise dos dados, procurou-se identificar os significados da alimentação para as pessoas com diabetes, articulando estes conteúdos analíticos com o cenário cultural da alimentação no Piauí e com as condições de vida e história particular de cada entrevistado, além de outros determinantes das pratica alimentares.

Em seguida aqueles conteúdos analíticos foram discutidos tendo como referências a literatura pesquisada e nossa própria experiência e vivência no atendimento em consultório, de pessoas com diabetes. Por último aqueles conteúdos, após a discussão crítica, foram classificados em categorias temáticas, correspondendo a diferentes dimensões do objeto de estudo. Algumas destas categorias eram previsíveis por antecipação e correspondiam a algumas hipóteses contidas no roteiro de entrevistas; outras, como o arraigado uso da medicina popular, destacaram-se durante a análise dos dados, aparecendo em quase todas as entrevistas sem que - certamente por descuido - nada se tivesse perguntado a respeito. Ficamos com o seguinte rol de categorias: a) relação com o profissional e a prescrição da 
dieta; b) prática alimentar dos entrevistados; c) não aceitação da doença; d) medicina popular; e) limitações econômicas; f) valor afetivo da alimentação.

As entrevistas foram realizadas em consonância com os ditames éticos da pesquisa em seres humanos. Cada pessoa foi informada quanto aos objetivos da pesquisa e da sua forma de participação, das gravações em áudio, da proteção do anonimato e resguardo do sigilo, bem como da opção de desistência do estudo em qualquer momento sem sofrerem qualquer prejuízo. Todas as informações necessárias foram dadas pela pesquisadora responsável, de modo que fosse possível dirimir quaisquer dúvidas dos entrevistados. A pesquisa foi aprovada pelo Comitê de Ética em Pesquisa da Escola Nacional de Saúde Pública (Protocolo CEP/ENSP nº 188/07).

\section{RESULTADOS CATEGORIZADOS}

O grupo estudado foi composto de vinte (20) pessoas, dezoito delas do sexo feminino. A idade variou entre trinta (30) e cinqüenta e nove anos (59). Quanto à ocupação, onze (11) eram servidores públicos, quatro (4) aposentados e os demais: lavrador, doméstica e comerciante. Apenas um entrevistado referiu não ter nenhuma renda, enquanto dezesseis recebiam mensalmente até três salários mínimos; os demais recebiam acima desse valor. Em relação à escolaridade, quatorze (14) referiram ter ensino fundamental e os demais, ensino médio completo. Todos residiam em bairros da periferia de Teresina. Metade dos entrevistados referiu ter hipertensão arterial; onze (11) faziam uso de medicação hipoglicemiante.

\section{a) Relação com o profissional e a prescrição da dieta}

A prescrição de dietas para pessoas com diabetes tipo 2 é um aliado importante no controle clínico-metabólico desse agravo, sendo conduta rotineira do profissional de nutrição. As pessoas são aconselhadas quanto à escolha de alimentos de acordo com suas necessidades fisiológicas, além da adequação ao diabetes e outras doenças associadas, se estas estiverem presentes.

A relação das pessoas com o profissional de saúde e com a dieta prescrita pode ser recortada, por sua vez, em três subcategorias, a saber: assimetria da relação com o profissional de saúde; conhecimento da dieta prescrita bem como das orientações nutricionais feitas pelos profissionais e reconhecimento da sua importância; e, ainda assim, o não seguimento estrito 
dessa dieta. O interesse dessa subcategorização reside na possibilidade de que estas relações tenham interferência na efetividade do aconselhamento alimentar. Pode-se antecipar que talvez não seja principalmente por desinformação que as pessoas tendem a não seguir estritamente as prescrições dietéticas, como se poderia supor.

a') Assimetria da relação com o profissional de saúde

A formação do profissional de saúde é essencialmente tecnicista, com quase nenhuma referência aos aspectos culturais que em algumas situações podem ser decisivos. A ênfase atual da política de saúde na integralidade da atenção reflete essa questão. O tecnicismo enviesa a compreensão do profissional tornando-o autoritário e pouco sensível ao diálogo e troca de saberes com as pessoas com diabetes. Por outro lado, essas pessoas vêem na figura do profissional o detentor do saber e neles depositam toda a confiança para o seu tratamento. Esse contexto pode levar a um conflito, pois a postura profissional é um fator que pode influenciar positivamente ou negativamente nas relações e na terapia. No estudo foi observada essa postura autoritária, que por sua vez é reproduzida pela família, podendo gerar sentimentos contraditórios de culpa, medo e raiva. Por outro lado existem também profissionais que parecem adotar uma postura compreensiva e dialógica com os seus clientes. As seguintes falas denotam essas situações:

[...] O médico me falou que eu podia comer qualquer fruta, qualquer alimento, mas que fosse só um pedaço, um pouco[...] eu tenho medo de comer manga mais eu como.Só que não satisfaz só com uma né?(AS)

Porque não vou dizer que aqui acolá eu não saio da dieta. Aío dotô brigou muito comigo, e a minha filha estava comigo, Ave Maria! Fui pra casa calada e ela (a filha) só era jogando na minha cara. Fiquei com tanta raiva!

$(V M)$

Tem uma coisa que eu gosto muito mas eu tenho vergonha de lhe contar [...] é a panelada, é lá uma vez porque faz mal também porque tem gordura (FI)

o que me interessa é o que o médico me diz e o mais eu vejo nos livros, revista também (MLL).

a") Conhecimento da dieta e demais orientações e reconhecimento de sua importância

Nos discursos dos sujeitos, observou-se que há conhecimentos sobre o plano alimentar e um reconhecimento da importância dessa prescrição feita pelo profissional de nutrição, bem 
como das recomendações feitas pelos outros profissionais de saúde. Nesse sentido, são elucidativas as seguintes falas:

Eles falam para a gente comer no café um pãozinho, certo, o pão eu não aumento, o cuscuz eu não aumento também. E a comida eu mesmo faço, porque quem faz a minha dieta sou eu mesma, é muito boa. Eu não gosto de comer, eu sou gorda mas eu não gosto de comer, chegar e comer muita comida [...] eu tomo café às 8:00 horas, aí quando é 10:00 horas eu como uma laranja ou uma banana, o almoço é 12:00 h ou 12:30 horas, aí pronto $(F A)$.

A médica da Família ela falou que a gente pode comer de tudo e de tudo nada [...] é um pouquinho de cada [...] mas a alimentação, o controle é do próprio diabético que faz. Eu acho que em primeiro lugar a gente tem que fazer a dieta. Eu tenho que comer controladamente (FA)

Eu como muita verdura no feijão, como muita salada. Minha alimentação melhorou com minha dotora nutricionista (FJN)

a",') Não seguimento estrito da dieta prescrita

Uma alimentação equilibrada é reconhecida, pelos entrevistados, como necessária para uma vida saudável e não apenas para o diabetes. Apesar disso, quase todos, senão todos os entrevistados seguem a prescrição dietética apenas de forma parcial. Alguns a seguem de forma estrita, mas só até a glicemia aproximar-se do normal, quando então abandonam a prescrição, retornando a ela quando os sintomas reaparecem. Outros seguem a dieta de forma continua, mas não em sua totalidade.

O negócio é muito ruim mais a gente tem que tentar. Tenho que fazer... pelo menos a metade $(V)$.

Me passaram uma dieta tão grande que eu andava fraquinha, me catando pelas paredes $(\mathrm{MCO})$.

É muito importante o papel da dieta na minha saúde e na saúde de qualquer pessoa. Seguir direitinho a dieta, o certo é esse. Só que é muito difícil isso aí, pelo menos prá mimé (TR).

É porque eu não obedeço como eu devia obedecer, quando eu estou sentindo qualquer problema aí eu obedeço, faço tudo direitinho e controlo, mas quando eu estou bem aí eu torno voltar tudo a estaca zero, como de tudo (TM).

A gente engorda também sem querer, mais não é que seja de comida... É serviço, preocupação $(D C)$. 
Não sigo a orientação da nutricionista. O difícil que tem é que ela passou para mim tomar no café da manha um pãozinho ou então biscoito [...]pra 9 horas eu comer uma fruta, no dia que tem eu como no dia que não tem eu não como [...] aí eu pego e aumento na comida. (AS)

A médica passou umas dietas aí to começando aos pouquinhos, mas é uma fome do inferno, e só faço uso da medicação (MTS).

\section{b) Prática alimentar dos entrevistados}

Quanto à prática alimentar tradicional dos entrevistados procurou-se saber da sua relação com as prescrições dietoterápicas e a influência da mídia no cotidiano (neste caso foilhes perguntado o que sabiam sobre alimentos diet/light). Reconstruíram-se duas subcategorias, a partir das constatações: que as praticas tradicionais predominam sobre as prescrições dietoterápicas e que a influência da mídia depende do poder aquisitivo das pessoas. As falas dos sujeitos demonstram claramente que outras dimensões têm forte influência no seu cotidiano.

b’) as práticas tradicionais predominam sobre as prescrições dietoterápicas

As práticas alimentares tradicionais foram construídas a partir de diferentes dimensões, diferentes culturas e também condicionadas por um cardápio relativamente escasso, em que quase sempre estão ausentes as verduras e as frutas. Neste caso a escassez foi historicamente compensada pela culinária variada, os mesmos alimentos sendo preparados de formas diversas. A dietoterapia, mesmo introduzindo outros alimentos, é considerada monótona, pouco apetitosa. O diabetes e o seu tratamento, portanto, causam um forte impacto nos hábitos rotineiros dos entrevistados. Aspectos familiares, culturais e afetivos se entrelaçam nesse contexto. Observamos nas falas:

Eu como mão de vaca, panelada, lasanha, às vezes, se eu comer em excesso eu sinto assim, meio tonta [...] sei que coisas gordurosas nada disso eu posso comer [...] Na minha casa varia muito, cada dia uma comida diferente, eu como cozido, maria isabel, tudo isso eu faço e como [...] aos finais de semana tem as filhas que vem a todas as refeiçôes comigo(TM).

É doutora se eu for dizer pra senhora a senhora até me reclama. Porque eu gosto de feijão com farinha [...] Mas a farinha me faz mal, acho que faz mal para todo mundo que é diabético [...] porque eu fui criada na roça, isso é de família (FI) 
Tem uma coisa que eu gosto muito mas eu tenho vergonha de lhe contar [...] é a panelada, é lá uma vez porque faz mal também porque tem gordura (FI)

b') a influência da mídia depende do poder aquisitivo

São muitos os fatores que permeiam o ato da alimentação que, construído inicialmente na infância, ao longo do tempo vai sofrendo influencias várias. É notório que a propaganda de alimentos interfere na compra e no consumo em determinadas camadas sociais. Nas falas dos entrevistados - que em geral tem baixo poder aquisitivo - observamos que apesar de terem acesso à televisão, a mídia tem pouca influencia no consumo de alimentos industrializados. Por outro lado, a veiculação de informações relacionadas à dieta poderia reforçar o plano dietoterápico do profissional. Verificamos também desconhecimento dos conceitos de diet e light para alguns entrevistados.

(Diet e light) Já vi. Não me interessa pelo seguinte: é coisa cara pra gente comprar... O dinheiro não dá $(A)$.

Propaganda não.[...] só o que a nutricionista fala ou as pessoas fala.[...] Mas é do mesmo jeito que ela fala na televisão. Eu acho até que a senhora já falou na televisão (FI).

Eu sei que é muito bom para mim, mais eu nunca comprei. Porque serve para mim me alimentar, e como é que se diz, combate a diabetes, combate as doencas que tem em cima de mim. Essa aí eu tô consciente. Uso adoçante $(A S)$.

o que me interessa é o que o médico me diz e o mais eu vejo nos livros, revista também (MLL).

Não sei a diferença entre os dois (diet e light) (LM).

\section{c) Não aceitação da doença}

A não aceitação da doença foi observada nas falas de algumas pessoas entrevistadas, onde, associada a essa rejeição, segue-se a não adesão completa à dieta, embora todos reconheçam sua importância no tratamento do diabetes. Em algumas falas essa rejeição à doença parece ser uma não aceitação do tratamento, seja medicamentoso ou dietético. Contudo pelo menos um dos entrevistados tinha uma compreensão peculiar - que lhe fora explicada por um profissional -, o que o fazia aceitar o diabetes com alguma serenidade. Outros aceitam a doença com resignação. As seguintes falas nos permitem refletir: 
Tem dia que acho enjoativo, tem dia que estou revoltada mesmo com a doença, porque eu nunca me acostumei com ela, eu sou revoltada, quando eu começo a fazer exames eu já começo me revoltar [...] porque eu ainda não me acostumei, foi uma coisa que não encaixou, quando eu pego o remédio eu só falto é morrer de chorar, revoltada com aquele tanto de remédio que eu tenho que engolir (FA).

No dia que vim pro médico que cheguei lá mostrando o exame foi uma confusão, até chorei de ódia [...] fiquei cheia de ódio [...] a senhora fica com raiva da gente porque a gente só quer seu bem (filhas) vai-te a porra, eu vou logo é morrer amanhã (VM).

Respeito ela, é uma doença que se a gente não respeitar ela, ela não respeita ninguém não, ela tortura a gente demais, ela mutila [...] diabete é perigosa (MCS).

O médico falou que diabete não é uma doença, é um problema de saúde: se eu me cuidar eu sou normal para trabalhar e conviver $(D L)$.

\section{d) Medicina popular: "Sou da Casca do Pau!"}

Nas falas dos entrevistados observou-se que a tradição está fortemente presente na forma como os entrevistados lidam com o Diabetes. Vale ressaltar que, no roteiro das entrevistas, o uso da medicina popular não foi perguntado diretamente; no entanto, todos os entrevistados fizeram referência a essa prática. Remédios caseiros, chás e outras preparações são bastante discutidos e trocados no seu meio social: família, amigos, vizinhos, colegas de trabalho. Há uma forte credibilidade e o uso parece ser mais ou menos indiscriminado, uma panacéia: "Se disser é prá isso eu tomo... Outro dia me indicaram não sei o quê do olho do gato” (VM). Por outro lado, alguns - como o chá da pata de vaca - são referidos na maioria das falas, e esse uso discriminado pode estar a indicar uma possível eficácia farmacológica.

Um único entrevistado, embora referindo conhecimento de chás e outros preparos, deles não faz uso, porque tem medo: "Vi um paciente morrer com chá" (MLL). Mas este caso parece uma exceção, pois o uso generalizado da medicina popular teria um princípio diverso, arraigado na cultura: se bem não faz, mal não fará. Além disso, sabe-se que o uso de chás e simpatias envolve sentimentos de fé e auto-cuidado e, nesse caso, mesmo sem um efeito farmacológico sobre o diabetes, não se pode duvidar de uma possível eficácia simbólica.

Mais de uma dezena de infusões ou preparações são citadas, destacando-se o chá da pata de vaca, como já foi referido. 
Berinjela, maracujá, casca do maracujá, bota pra secar, pisa e faz a farinha. Usa como farinha em cima da comida, né?E outras coisas mais que ensinam. Água dentro da sapucaia, chá de folha de limão com alfazema. Eu faço por época (AM)

Às vezes eu passei pela hidroginástica e as colegas me dão nome de chá. Agora tô tomando um que ela me deu, não sei o que do olho do gato [..] essa minha colega disse que a dela tava lá em cima, tomou e desceu.(VM)

Falar a verdade eu sou da casca do pau. Eu faço garrafada lá em casa. Boto a casca de molho e tomo. Aí tomei muita pata de vaca, que me ensinaram que era bom, né?Aí eu vou no mercado e compro umas cascas de pau que diz que serve prá isso, serve pra aquilo, pra aquilo outro. Eu mesmo pego e misturo tudo. Fico tomando um pouquinho todo dia [...] se disser é prá isso, eu tomo (MCS).

\section{e) Limitações econômicas: "Seguir o pé da letra não tem condição!”.}

Observamos nas falas de alguns dos entrevistados que o poder aquisitivo é um componente decisivo para aquisição de alimentos e é citado como uma justificativa limitante da compra e da freqüência de consumo de determinado tipo de alimento - frutas, por exemplo - o que interfere na adesão à dieta. Além disso, “comida mesmo”, parece incluir apenas os alimentos que fazem parte do cardápio tradicional.

Já vi (sobre diet e light). Não me interessa pelo seguinte... é coisa cara para a gente comprar, porque o dinheiro não dá. Passá a comprar isso aí e seguir o pé da letra, não tem condições, o salário daqui... desse jeito aí não dá $(A M)$

Gosto de comer comida mesmo. Eu gosto de comer carne de porco, à vontade, bode, ah sim... frango eu já abusei, como mas não gosto mais. Fruta, assim... se eu pudesse, eu me arreiava em cima das frutas, pois é. A gente não tem condição de tá se alimentando assim, né?(AS)

Eu não tenho condições de fazer a dieta. Os motivos são os seguintes: porque essa renda só sai de mim, né?[...] Prá mim é, porque se eu tivesse condições eu seguia a dieta toda direitinho. Comprava meus alimentos, tudo. Hoje não sei o que é uma fruta. (AS).

Verdura, repolho, couve... eu já abusei. Entra assim, mas é meio atravessado (A).

\section{f) $O$ valor afetivo da alimentação}

É interessante lembrar que a palavra comer tem raiz latina aproximada com comum e comungar. Parece denotar que comer é um ato que se deve praticar comungando com outras pessoas. De fato os hábitos alimentares, desde a infância, tradicionalmente são adquiridos e 
construídos no seio familiar, todos à mesa nas horas de refeições. Evidentemente também é o lugar e a hora do fortalecimento dos laços afetivos, um genuíno ritual social e familiar. Daí o destaque para essa categoria.

O preparo dos alimentos para a família é, na divisão tradicional das tarefas domésticas, um encargo feminino, geralmente da mãe de família, o que se pode configurar como fazendo parte da sua identidade social: para estas mulheres pode ser dramática a situação de preparar com carinho os alimentos e estar proibida de saboreá-los. Por outro lado, para algumas famílias em que as mulheres também estão inseridas no mercado de trabalho, os papéis tradicionais são postos de lado e todos têm que saber cozinhar: aqui se perde também o ritual de comunhão familiar na alimentação, mas não de todo, pois às vezes a família se reúne nos finais de semana ou nas datas comemorativas.

Alguns entrevistados referem-se a doces como se tivessem um gostinho de infância, e ainda outros lembram com saudade o sabor de iguarias agora interditadas.

Tem minha filha que trabalha e faz (preparo da alimentação) $e$ no dia que ela não faz eu faço, quando num tá nem ela nem eu, meu marido faz do jeito que eu posso comer, porque ele tem problema de pressão alta. Todo mundo cozinha (MCS).

No dia do aniversario que a gente, quer ver toda a família junta, né? Aí a gente faz tanta comida... Aí eu como mesmo de tudo, de tudo um pouco. Depois eu faço exames de tudo: figo, rim, bofe, coração, eu faço tanto exame (MCS).

Quem escolhe tudo sou eu, quando meu marido recebe dinheiro ele vai fazer as compras, quando eu recebo eu vou mais minhas filhas (RCO).

O problema é que eu gosto muito é de doce... Gostava. Bombom, chocolate, doce de leite, doce de coco, rapadura... essas coisa a gente foi criada, naquele tempo que a gente comia mesmo essas coisas. De primeiro eu gostava de fazer doce de leite e de mamão, agora doce nenhum porque eu não posso comer, então não posso nem ver (MGN).

Aos finais de semana tem as filhas que vêem a todas as refeições comigo. $O$ costume é porque na minha casa sempre teve lasanha dia de domingo, é uma coisa que sempre tem (TM).

Às vezes eu sinto saudade de um picadinho com maxixe e abóbora (DC). 


\section{DISCUSSÃO}

\section{Prática alimentar e diabetes: desafios para a vigilância em saúde}

A análise compreensiva permitiu identificar, na fala dos entrevistados, diversos sentidos na sua percepção da alimentação, correlacionados ao contexto em que vivem essas pessoas, sua cultura, seu cotidiano e suas condições de vida. A experiência com a própria enfermidade é fonte de conhecimento sobre o diabetes e, da mesma forma, o reconhecimento dos benefícios trazidos pela terapia e demais recomendações profissionais. Ainda assim, fatores de ordem extremamente complexos - conforme anteriormente expostos - dificultam o seguimento estrito da terapêutica. Acresce que parte dos profissionais - não todos desconhece aquela complexidade, lidando com o diabetes de forma meramente biológica e tecnicista. Esse desconhecimento leva a uma postura autoritária e não dialógica com as pessoas afetadas pelo diabetes, uma não compreensão das dificuldades reais que, por sua vez, não facilita a adesão ao tratamento, na medida em que não estabelece um vínculo de confiança na relação com aquelas pessoas. Convém ressaltar que esta postura autoritária, da qual resulta uma relação de assimetria com a clientela, também é um fato cultural, nesse caso gerado a partir da formação essencialmente tecnicista destes profissionais. Ainda assim há sinais de mudança, como detectado em várias entrevistas e particularmente em uma que relata uma compreensão interessante, ressignificada a partir da explicação de um profissional: que o diabetes não seria uma doença, mas um problema de saúde que, bem controlado, não limitava o "trabalhar e conviver".

Atualmente a Política Nacional de Humanização da Saúde (PNH), do Ministério da Saúde, tem como diretriz a construção de relações solidárias e comprometidas entre os profissionais e sua clientela, destacando os aspectos subjetivos além da valorização dos diferentes sujeitos. A humanização em saúde supõe a troca de saberes entre profissionais de saúde e população, valorizando as pessoas em suas individualidades, estabelecendo vínculos solidários e estimulando a participação coletiva. Desta forma, além de uma atitude respeitosa e cidadã, espera-se também uma maior efetividade das prescrições técnicas.

Mas mesmo a ausência de vínculo solidário não impede que as pessoas apreendam ou ressignifiquem o que lhes é dito pelos profissionais: parece realmente não ser por desinformação que as pessoas acompanhadas por especialistas apresentam aquelas dificuldades. Nas falas dos entrevistados, a fome que sentem com a dieta é uma dessas 
dificuldades, bem como o fato de muitos não gostarem de verduras, por exemplo. Alguns tomam apenas a medicação, sem seguir a dieta. A maioria, ou faz dieta parcial (comer de tudo um pouco) ou intermitente (quando sentem as alterações clínicas ou constatam a glicemia alterada). Assim, podemos concluir que a orientação meramente técnica parece não ser suficiente para a mudança dos hábitos, sendo necessário um diálogo que compreenda todo o contexto que envolve estes hábitos.

RAYNAUT $^{45}$ discute a busca de novas abordagens nas praticas dos profissionais de saúde, apontando que sua atuação deve ser direcionada para indivíduos ou coletividades, no sentido de curar e educar, admitindo que as pessoas vivem em redes sociais, assumindo comportamentos próprios dessas redes. A mudança configura-se como um desafio que passa pela abordagem da antropologia da saúde e exige um olhar interdisciplinar.

No conflito gerado por uma prescrição dietética que claramente beneficia a saúde, mas não satisfaz outras necessidades, predominam as praticas cotidianas de alimentação. $O$ diabetes é um componente forte nas falas, as pessoas reconhecem sua gravidade e algumas vivenciaram a dramática situação de familiares com o mesmo problema. Talvez se o hábito alimentar dos humanos fosse um ato apenas fisiológico, não houvesse tanta dificuldade para a mudança. Mas não: a cultura alimentar, a regionalização das preparações, os costumes e as tradições estão largamente arraigados na vida dessas pessoas. A construção das práticas alimentares, que se diferencia em cada grupo, está inserida na cultura, ocupando posição central no aprendizado social. ${ }^{\mathbf{2 4}}$ Nessa direção, as práticas alimentares devem ser compreendidas desde a amamentação, introdução de alimentos complementares e até a adoção da alimentação familiar. ${ }^{32}$ Estas práticas, portanto, são construídas ao longo do tempo pelos grupos sociais, que lhes vão atribuindo significados socializados em ritos e preferências, e que constituem um aprendizado que passa de pais para filhos.

Embora seja inequívoca a influência da mídia nas práticas alimentares, no grupo entrevistado este aspecto se mostrou com pouca ou quase nenhuma relevância. Este grupo, composto por usuários de um serviço público, moradores de bairros periféricos de Teresina ou de cidades interioranas, tem pouco poder aquisitivo, o que dificulta o acesso aos bens apregoados pela mídia. Mas também a presença de uma forte cultura alimentar parece oferecer resistência a estes pregões. Por outro lado algumas falas relevam a importância da mídia quando esclarece aspectos relacionados à diabete e seu tratamento. A mídia, bem direcionada, também tem papel importante na veiculação de informações em saúde, configurando-se assim como um instrumento importante de promoção da saúde. 
Na categoria não aceitação da doença, a análise das entrevistas revelou quase sempre um sentimento de forte medo das conseqüências do diabetes, associado a conflitos de várias ordens, expressos geralmente na recusa ou impossibilidade de seguir de forma estrita as recomendações dietéticas, atividades físicas e até mesmo medicamentos. O medo e a culpa gerada pelos conflitos certamente não contribuem para o equilíbrio orgânico. Acresce que a divulgação do conhecimento sobre o diabetes, seja oficial ou midiático, geralmente apela para as consequências dramáticas da doença, no intuito de reforçar a adesão ao tratamento. Neste caso podemos afirmar que a educação e a comunicação em saúde apelam para os sentimentos negativos em relação ao problema. Seguindo esta linha investigativa na análise comparativa dos dados detectou-se uma outra ordem de conflito, de nível conceitual, embora não expresso de forma explícita nas falas, mas passível de detecção metodológica. Qual seja: que o diabetes é considerado tecnicamente como uma doença grave; mas também poderia ser visto conforme a fala de um dos entrevistados aqui já destacado - como um problema de saúde que pode ser controlado, não sendo necessariamente uma doença. Neste último caso o diabetes poderia ser classificado como um agravo e não como uma doença grave, o que não nos parece absurdo. Abolindo-se o apelo aos sentimentos negativos acreditamos que a educação e a comunicação em saúde teriam maior efetividade.

No Brasil a crítica à educação em saúde tradicional tem sido intensa nos últimos anos, trazendo importantes desenvolvimentos teóricos. ${ }^{33}$ No entanto estes aportes ainda não foram incorporados às práticas oficiais, não têm sido traduzidos em intervenções concretas. Sob este ângulo, acreditamos que as práticas profissionais de educação deveriam estar abertas à possibilidade de trabalhar com as representações que as pessoas constroem sobre os seus problemas de saúde, incorporando elementos que façam sentido no contexto geral do problema, e não apenas banalizando a linguagem, como muitas vezes acontece - uma forma ilusória de comunicação. Evidentemente essa compreensão já é aceita e recomendada oficialmente pelas políticas de saúde, mas faltam ainda clareza e estratégias para sair do discurso teórico e político para a concretude das práticas.

Outra categoria destacada na fala dos entrevistados foi a prática arraigada da medicina popular. Todos fizeram referência ao uso de algum tipo de chá ou preparo caseiro, com objetivo curar ou melhorar o diabetes. O respeito à tradição e os rituais de auto-cuidado se entrelaçam nestas práticas. O uso é mais ou menos indiscriminado, uma verdadeira panacéia, mas com a segurança ditada pela experiência coletiva: se bem não faz, mal não fará. Por outro lado, alguns chás, como o de pata de vaca, têm um uso bastante discriminado, havendo referências explícitas à sua eficácia específica, a partir da experiência das pessoas. Sabe-se 
que o chá de pata de vaca é amplamente usado no Brasil no tratamento do diabetes, e esta poderia mesmo ser uma pista antropológica para o teste farmacológico da eficácia dos seus princípios ativos.

Outro aspecto - referente ainda à medicina popular - que se destaca nas entrevistas é a forma dinâmica como estes usos, advindos de um tempo longo, se atualizam e se tornam presentes no cotidiano das pessoas. Alguns usos são de tradição familiar, outros são atualizados nas redes sociais de vizinhança, amigos, colegas de trabalho ou outras instâncias associativas, bem como a indicação por pessoas que têm o mesmo problema de saúde. As pessoas sabem também que os chás não interferem na terapia especializada, podendo ser usados de forma concomitante, como tratamento auxiliar

Na categoria "limitações econômicas da prática alimentar" o poder aquisitivo surge como um fator limitante da compra e freqüência de consumo de determinados alimentos, e em algumas falas isto aparece como justificativa forte para a não adesão à dieta prescrita. Aqui destacamos, embora sejam óbvios, dois aspectos importantes: primeiro, o poder aquisitivo deve ser levado em consideração ao se prescrever um plano alimentar; segundo, a importância do diálogo na educação nutricional, principalmente pelo profissional de nutrição. A prescrição dietoterápica deve contemplar todas as necessidades nutricionais dos indivíduos, mas levando em consideração outros fatores, dentre eles o poder aquisitivo. O profissional deve estar habilitado para reconhecer, dentre todos os recursos alimentares disponíveis em determinado meio, aqueles mais acessíveis às camadas populares, muitas vezes desconhecidos pelas pessoas que deles necessitam. Esse modo interativo de conduzir a orientação dietética e a educação nutricional, seja referenciado ao poder aquisitivo das pessoas ou outros fatores intervenientes como hábitos e cultura, está em consonância com o pensamento de vários autores. ${ }^{19,32,33}$

Com a categoria "valor afetivo da alimentação", pretendia-se denotar a comensalidade como um fator de fortalecimento dos laços afetivos familiares, e as falas dos entrevistados demonstram a presença desse aspecto em situações várias, seja no cotidiano, no almoço dos domingos ou nas datas comemorativas. O caráter social da alimentação está presente desde o nascimento, onde o ato da amamentação está precipuamente revestido por laços de afeto e proteção, envolvendo desde então a relação com o outro. ${ }^{34}$ Essa relação com o outro, sempre revestida de laços afetivos, aparece, na fala de nossos entrevistados, já na divisão das tarefas domésticas e até a escolha, compra e preparo dos alimentos, configurando papéis sociais no seio familiar. Estes papéis podem ser mais ou menos bem definidos (tradição), ou - o que é mais comum - indefinidos, misturados, alternados, de acordo com as 
estratégias de sobrevivência das famílias. Neste caso configuram-se novos papéis sociais, refletidos na comensalidade. Estes fatos são largamente referidos na literatura: a comensalidade socializa os homens, o convívio é a imagem da vida em comum (cum vivere).$^{27}$ A dimensão sociocultural da alimentação marca a identidade de grupo e estabelece fronteiras sociais. ${ }^{17,34}$

O valor afetivo da alimentação - foi possível detectar um outro aspecto, de ordem menos coletiva e mais subjetiva: o alimento associado a recordações, talvez vivências passadas. Também a saudade foi referida como um sentimento associado a alguns alimentos atualmente proibidos. Novamente os significados da alimentação surgem com forte simbolismo, e sem exageros podemos afirmar que ela deva ser constituinte da própria identidade dos indivíduos. E assim achamos que possamos contribuir para a compreensão das múltiplas dimensões da alimentação na vida das pessoas, bem como da importância que isto se reveste para a prática profissional do nutricionista.

\section{CONSIDERAÇÕES FINAIS}

As práticas alimentares, compreendidas em todas as suas dimensões, são construídas ao longo do tempo e se atualizam no convívio em redes sociais, concretizando-se nos hábitos cotidianos dos indivíduos. O estudo desse tema nos possibilitou atingir os objetivos propostos, na medida em que nos ajudou a entender com mais profundidade as dificuldades que as pessoas com diabetes têm para aderir à dieta prescrita e às recomendações nutricionais; conhecer a dimensão valorativa das praticas alimentares e descrever as percepções e ressignificações do grupo pesquisado. Nestas considerações finais destacamos os principais achados da pesquisa, não a guisa de conclusões, - que este tema permanecerá sempre aberto e inconcluso - mas no intuito de subsídios para uma reflexão crítica da conduta do profissional que lida com o diabetes.

- Os sujeitos entrevistados são conscientes da importância da dieta para o diabetes, e isto é apreendido no contato com os profissionais de saúde (principalmente médicos e nutricionistas) e na própria experiência com a enfermidade e seu tratamento, podendo este aprendizado ser reforçado pela mídia.

- A prática alimentar é construída pelos sujeitos tendo como referência seu espaço social, o que inclui dimensões tão várias como a cultura e o poder aquisitivo.

- O espaço culinário e os hábitos de consumo familiares são perpassados por valores afetivos, configurando-se então como uma dimensão maior nas praticas 
alimentares e, por conseguinte, na saúde das pessoas com diabetes. Isso certamente contribui para que as práticas alimentares dos sujeitos predominem sobre as prescrições dietoterápicas.

- Existe um temor com relação às conseqüências do diabetes, e isto é observado quando os entrevistados se reportam a determinados alimentos que acham que são deletérios para seu organismo. A dramaticidade dos casos de cegueira e mutilações também é conhecida. Acresce que a divulgação do conhecimento sobre a enfermidade reforça este sentimento negativo.

- É importante o envolvimento dos familiares no processo educativo, tendo em vista que também a família pode proceder de forma autoritária, reproduzindo a conduta de alguns profissionais no cotidiano alimentar das pessoas com diabetes, gerando o conflito e a culpa, que podem ser deletérias à saúde dessas pessoas.

- O estudo e sua abordagem compreensiva esperam poder contribuir com a Vigilância em Saúde no campo da alimentação e nutrição, entendendo que esta vigilância deva ser perpassada pelas políticas de promoção da saúde e humanização da atenção.

- A Vigilância em Saúde das doenças crônicas não transmissíveis deve privilegiar as realidades locais. O Brasil tem grande dimensão e heterogeneidade social, econômica e cultural, e essa diversidade condiciona tanto o perfil epidemiológico de doenças e agravos como a forma de tratamento individual ou controle coletivo. A questão epidemiológica não se reduz a meras distribuições de freqüências.

- Entendemos que a abordagem qualitativa na coleta dos dados é complementar à epidemiologia descritiva, sendo imprescindível para uma maior aproximação com as realidades locais, desta forma podendo trazer subsídios para uma promoção e educação em saúde mais efetivas, privilegiando características peculiares de cada região. 


\section{REFERÊNCIAS}

1 - BRASIL, SECRETARIA DE VIGILÂNCIA EM SAÚDE. Saúde Brasil 2005: Uma análise da situação de saúde. Brasília: Ministério da Saúde; 2005.

2 - BRASIL, SECRETARIA DE VIGILÂNCIA EM SAÚDE. Saúde Brasil 2006: Uma análise da situação de saúde. Brasília: Ministério da Saúde; 2006.

3 - MALTA DC, CEZÁRIO AC, MOURA L, MORAIS NETO OL, SILVA JÚNIOR JB. A construção da vigilância e prevenção das doenças não transmissíveis no contexto do Sistema Único de Saúde. Epidemiologia e Serviços de Saúde. 2006;15(1): 47-65.

4 - LESSA I. Doenças Crônicas Não Transmissíveis no Brasil: um desafio para a complexa tarefa da vigilância. Ciência \& Saúde Coletiva. 2004; 9(4):931-943.

5 - BRASIL, SECRETARIA DE VIGILANCIA EM SAÚDE. A Vigilância, o controle e a prevenção de doenças crônicas não transmissíveis: DCNT no controle do Sistema Único de Saúde brasileiro. Brasília: Ministério da Saúde; 2005.

6 - BATISTA FILHO M, RISSIN A. A transição nutricional no Brasil: tendências regionais e temporais. Cad. de Saúde Pública. 2003; 19 (1): 181-191.

7 - Chronic diseases. WHO - World Health Organization. Disponível em: http://www.who.int/topics/chronic_diseases/en. Acessado em: 18/08/2008.

8 - Sociedade Brasileira de Diabetes. Diretrizes da Sociedade Brasileira de DiabetesTratamento e Acompanhamento do Diabetes Mellitus. Rio de Janeiro: Diagraphic, 2006.

9 - Sociedade Brasileira de Cardiologia. IV Diretrizes sobre Dislipidemias e Prevenção da Aterosclerose. Arq. Bras. de Cardiologia. 2007-Udeme 88 (1).

10 - BRASIL, MINISTÉRIO DA SAÚDE. Análise da Estratégia Global para Alimentação Saudável, Atividade Física e Saúde. (Documento realizado pelo Grupo Técnico Assessor Instituído pela Portaria do Ministério da Saúde no 596, de 8 de abril de 2004).

11 - MALERBI D, FRANCO LJ. The Brazilian Cooperative Group on the study the Prevalence of Diabetes Mellitus and Impaired Glucose Tolerance in the urban Brazilian population aged 30-69 years. Diabetes Care. 1992;15(11): 1509-1516.

12 - TORQUATO MTCG, MONTENEGRO Jr RN, VIANA LAL, SOUZA RAHG, IANNA CMM, LUCAS JCB et al. Prevalence of diabetes mellitus and impaired glucose tolerance in the urban population aged 30-69 years in Ribeirão Preto (São Paulo), Brazil. São Paulo Med J. 2003; 121(6): 24-30.

13 - Sociedade Brasileira de Cardiologia. I Diretriz Brasileira de Diagnóstico e Tratamento da Síndrome Metabólica. Arq. Bras. de Cardiologia, 2005;84(1). 
14 - SARTORELLI D. S, FRANCO L J. Tendências do diabetes mellitus no Brasil: o papel da transição nutricional. Cad de Saúde Pública. Rio de Janeiro. 2003; 19 ( 1): 529536.

15 - LIMA-COSTA MF, PEIXOTO SU, GIATTI L. Tendências da mortalidade entre idosos brasileiros (1980-2000). Epidemiologia e Serviços de Saúde. 2004;13(4):217-228.

16 - KAC G, VELÁSQUEZ-MELÉNDEZ G. A transição nutricional e a epidemiologia da obesidade na América Latina. Cadernos de Saúde Pública. 2003; 19(1) S4-S5.

17 - POULAIN JP, PROENÇA RPC. O espaço social alimentar: um instrumento para o estudo dos modelos alimentares. Revista Nutricional de Campinas. 2003; 16(3): 245-256.

18 - CORNELLI G. Os sentidos da alimentação: para uma antropologia filosófica da alimentação. In: MIRANDA DS, CORNELLI G. Cultura e Alimentação. Saberes Alimentares e Sabores Culturais. São Paulo: SESC, 2007: 25-34.

19 - GARCIA RWD. Reflexos da globalização na cultura alimentar: considerações sobre a alimentação urbana. Revista de Nutrição. 2003; 16(4).

20 - MURRIETA RSS. Dialética do sabor: alimentação, ecologia e vida cotidiana em comunidades ribeirinhas da Ilha de Ituqui, Baixo Amazonas, Pará. Revista de Antropologia. 2001; 44(2): 40-88

21 - MACIEL ME. Uma cozinha à Brasileira. Estudos Históricos. 2004; 33: 1-16.

22 - SAGLYO-YATZIMIRSKY. A comida dos favelados. Estudos Avançados. 2006; 20(58): 123-132.

23 - RAYNAUT C. Interfaces entre a antropologia e a saúde: em busca de novas abordagens conceituais. Revista Gaúcha de Enfermagem. 2006; 24(2): 149-165.

24 - MINTZ SW. Comida e Antropologia :uma breve revisão. Revista Brasileira de Ciências Sociais. 2001; 16(47): 32-41.

25 - CARNEIRO H. Comida e Sociedade. Rio de Janeiro: Campus, 2003.

26 - CARNEIRO H. História da alimentação no Brasil. In: MIRANDA DS, CORNELLI G. Cultura e Alimentação. Saberes Alimentares e Sabores Culturais. São Paulo: SESC, 2007. pág. 71-79.

27 - FLANDRIN JL, MONTANARI M. História da alimentação (tradução de Luciano Vieira Machado e Guilherme J. F. Teixeira).São Paulo: Estação Liberdade, 1998.

28 - POLIT DF, HUNGLER BP. Fundamentos da Pesquisa em Enfermagem. 3 ed., Porto Alegre: Artes Médicas, 2003

29 - MINAYO MCS. O desafio do conhecimento: pesquisa qualitativa em saúde. 6 ed., Rio de Janeiro; Hucitec,1999. 
30 - BARDIN L. Análise de Conteúdo. Lisboa/Portugal: edições 70, 2006. (título original: L'Analyse de Contenu) Tradução: Luis Antero Reto e Augusto Pinheiro

31 - FRANCO MLPB. Análise de Conteúdo. Brasília, 2ª ed: Liber Livro, 2005.

32 - ROTEMBERG S, DE VARGAS S. Práticas Alimentares e o cuidado da saúde: da alimentação da criança e da família. Revista Brasileira de Saúde Matern Infantil. 2004; 4(1): 85-94.

33 - GAZINELLI MF et al. Educação em saúde: conhecimentos, representações sociais e experiência da doença. Cadernos de Saúde Pública. 2005; 21(1): 200-206.

34 - ROMANELLI G. O significado da alimentação na família: uma visão antropológica. Medicina. 2006; 39(3), 333-339. 


\section{CONSIDERAÇÕES FINAIS}

As práticas alimentares, compreendidas em todas as suas dimensões, são construídas ao longo do tempo e se atualizam no convívio em redes sociais, concretizando-se nos hábitos cotidianos dos indivíduos. O estudo desse tema nos possibilitou atingir os objetivos propostos, na medida em que nos ajudou a entender com mais profundidade as dificuldades que as pessoas com diabetes têm para aderir à dieta prescrita e às recomendações nutricionais; conhecer a dimensão valorativa das praticas alimentares e descrever as percepções e ressignificações do grupo pesquisado. Nestas considerações finais destacamos os principais achados da pesquisa, não a guisa de conclusões, - que este tema permanecerá sempre aberto e inconcluso - mas no intuito de subsídios para uma reflexão crítica da conduta do profissional que lida com o diabetes.

- Os sujeitos entrevistados são conscientes da importância da dieta para o diabetes, e isto é apreendido no contato com os profissionais de saúde (principalmente médicos e nutricionistas) e na própria experiência com a enfermidade e seu tratamento, podendo este aprendizado ser reforçado pela mídia.

- A prática alimentar é construída pelos sujeitos tendo como referência seu espaço social, o que inclui dimensões tão várias como a cultura e o poder aquisitivo.

- O espaço culinário e os hábitos de consumo familiares são perpassados por valores afetivos, configurando-se então como uma dimensão maior nas praticas alimentares e, por conseguinte, na saúde das pessoas com diabetes. Isso certamente contribui para que as práticas alimentares dos sujeitos predominem sobre as prescrições dietoterápicas.

- Existe um temor com relação às conseqüências do diabetes, e isto é observado quando os entrevistados se reportam a determinados alimentos que acham que são deletérios para seu organismo. A dramaticidade dos casos de cegueira e mutilações também é conhecida. Acresce que a divulgação do conhecimento sobre a enfermidade reforça este sentimento negativo.

- É importante o envolvimento dos familiares no processo educativo, tendo em vista que também a família pode proceder de forma autoritária, reproduzindo a conduta de alguns profissionais no cotidiano alimentar das pessoas com diabetes, gerando o conflito e a culpa, que podem ser deletérias à saúde dessas pessoas. 
- O estudo e sua abordagem compreensiva esperam poder contribuir com a Vigilância em Saúde no campo da alimentação e nutrição, entendendo que esta vigilância deva ser perpassada pelas políticas de promoção da saúde e humanização da atenção.

- A Vigilância em Saúde das doenças crônicas não transmissíveis deve privilegiar as realidades locais. O Brasil tem grande dimensão e heterogeneidade social, econômica e cultural, e essa diversidade condiciona tanto o perfil epidemiológico de doenças e agravos como a forma de tratamento individual ou controle coletivo. A questão epidemiológica não se reduz a meras distribuições de freqüências.

- Entendemos que a abordagem qualitativa na coleta dos dados é complementar à epidemiologia descritiva, sendo imprescindível para uma maior aproximação com as realidades locais, desta forma podendo trazer subsídios para uma promoção e educação em saúde de mais efetivas, privilegiando características peculiares de cada região. 


\section{REFERÊNCIAS}

1 - CARVALHO F, et al. O processo de transição epidemiológica e iniqüidade social: o caso de Pernambuco. Revista da Associação de Saúde Pública do Piauí; Teresina, 1998;1(2):107-119.

2 - POSSAS C. A especificidade do quadro sanitário no Brasil: principais características. In: Epidemiologia e Sociedade: heterogeneidade estrutural e saúde no Brasil: São Paulo: Hucitec, 1989:19-97.

3 - VERMELHO LL, MONTEIRO MFG. Transição Demográfica e Epidemiológica. IN: MEDRONHO RA(organizador). Epidemiologia. São Paulo: Atheneu, 2005: 91- 103.

4 - MALTA DC, CEZÁRIO AC, MOURA L, MORAIS NETO OL, SILVA JÚNIOR JB. A construção da vigilância e prevenção das doenças não transmissíveis no contexto do Sistema Único de Saúde. Epidemiologia e Serviços de Saúde. 2006;15(1): 47-65.

5 - BRASIL, SECRETARIA DE VIGILÂNCIA EM SAÚDE. Saúde Brasil 2005: Uma análise da situação de saúde. Brasília: Ministério da Saúde; 2005.

6 - BRASIL, SECRETARIA DE VIGILANCIA EM SAÚDE. A Vigilância, o controle e a prevenção de doenças crônicas não transmissíveis: DCNT no controle do Sistema Único de Saúde brasileiro. Brasília: Ministério da Saúde; 2005.

7 - BATISTA FILHO M, ASSIS AM, KAC G. Transição nutricional: conceitos e características. In: KAC G(organizador). Epidemiologia Nutricional. Rio de Janeiro: Atheneu; 2007; 445-460.

8 - BATISTA FILHO M, RISSIN A. A transição nutricional no Brasil: tendências regionais e temporais. Cad. de Saúde Pública. 2003; 19 (1): 181-191.

9 - BRASIL, SECRETARIA DE VIGILÂNCIA EM SAÚDE. Saúde Brasil 2006: Uma análise da situação de saúde. Brasília: Ministério da Saúde; 2006.

10 - OPAS. Organização Pan Americana de Saúde.

11 - SILVA JUNIOR J B da et al. Doenças e Agravos não transmissíveis, bases epidemiológicas. In: ROUQUAYROL M Z, ALMEIDA FILHO N de. Epidemiologia e Saúde. Rio de Janeiro: Medsi, 2003.

12 - LESSA I. Doenças Crônicas Não Transmissíveis no Brasil: um desafio para a complexa tarefa da vigilância. Ciência \& Saúde Coletiva. 2004; 9(4):931-943.

13 - ESCODA MSQ. Para a crítica da transição nutricional. Ciência \& Saúde Coletiva. 2002: 7(2):219-226.

14 - BRASIL, MINISTÉRIO DA SAÚDE. Análise da Estratégia Global para Alimentação Saudável, Atividade Física e Saúde. (Documento realizado pelo Grupo Técnico Assessor Instituído pela Portaria do Ministério da Saúde nº 596, de 8 de abril de 2004). 
15 - Sociedade Brasileira de Diabetes. Diretrizes da Sociedade Brasileira de Diabetes Tratamento e Acompanhamento do Dibetes Mellitus. Rio de Janeiro: Diagraphic, 2006.

16 - Sociedade Brasileira de Cardiologia. IV Diretrizes sobre Dislipidemias e Prevenção da Arterosclerose. Arq. Bras. de Cardiologia. 2007-Udeme 88 (1).

17 - MONTEIRO CA, MOURA EC, JAIME PC, LUCCA A, FLORINDO AA, FIGUEIREDO ICR e col. Monitoramento de fatores de risco para doenças crônicas por entrevistas telefônicas. Rev. Saúde Pública. 2005: 39(1): 47-57.

18 - World Health Organization [WHO]. Diet, nutrition and prevention of chronic diseases. Geneva; 2003.

19 - HU FB. \& WILLET W C. Optimal diets for prevention of coronary heart disease. JAMA. 2002; 288: 2569-2578.

20 - Sociedade Brasileira de Cardiologia. I Diretriz Brasileira de Diagnóstico e Tratamento da Síndrome Metabólica. Arq. Bras. de Cardiologia, 2005;84(1).

21 - BARRETO ML, CARMO EH. Situação de saúde da população brasileira: tendências históricas, determinantes e implicações para as políticas de saúde. Informe Epidemiológico do SUS. 1994;3(4): 7-34.

22 - SCHRAMM JMA, OLIVEIRA AF, LEITE IC, VALENTE JG, GADELHA AMJ, PORTELA MC e col. Transição epidemiológica e o estudo da carga de doença no Brasil. Ciência \& Saúde Coletiva. 2004; 9(4): 897-908.

23 - HOUAIS A, VILLAR MS. Minidicionário Houaiss da língua portuguesa. Rio de Janeiro: Objetiva; 2004.

24 - KAC G, VELÁSQUEZ-MELÉNDEZ G. A transição nutricional e a epidemiologia da obesidade na América Latina. Cadernos de Saúde Pública. 2003; 19(1) S4-S5.

25 - VASCONCELOS FAG. Tendências históricas dos estudos dietéticos no Brasil. História, Ciência e Saúde. 2007;14(1):197-219.

26 - INSTITUTO BRASILEIRO DE GEOGRAFIA E ESTATÍSTICA (IBGE). Endef (Estudo Nacional de Despesas Familiares): resultados preliminares. Brasília: IBGE, 1977.

27 - INSTITUTO BRASILEIRO DE GEOGRAFIA E ESTATÍSTICA (IBGE). Pesquisa de Orçamentos Familiares no Brasil, 2002/2003: antropometria e análise do estado nutricional de crianças e adolescentes no Brasil. Rio de Janeiro: IBGE, 2006.

28 - INSTITUTO BRASILEIRO DE GEOGRAFIA E ESTATÍSTICA (IBGE). /MINISTÉRIO DO PLANEJAMENTO (MP)/MINISTÉRIO DA SAÚDE (MS). Pesquisa de Orçamentos Familiares, 2002-2003: análise da disponibilidade domiciliar de alimentos e do estado nutricional no Brasil. Rio de Janeiro: IBGE, 2004.

29 - MELÉNDEZ GV, KAC G. A Transição Nutricional e a Epidemiologia da Obesidade na América Latina. Cad. Saúde Pública, Rio de Janeiro, 2003; 19 (1): S4 S5. 
30 - História do Diabetes. Primeiros relatos. Sociedade Brasileira de Diabetes. Disponível em http://www.diabetes.org. Acessado em: 07/09/2007.

31 - Histórico do Diabetes. Disponível em http://www.geocities.com. Acessado em: 18/08/2008.

32 - American Diabetes Association. Report of the expert committe on the diagnosis and classification of diabetes mellitus. Diabetes Care. 1998; 28(1): S5.

33 - Sociedade Brasileira de Diabetes. Consenso Brasileiro sobre diabetes: diagnóstico e classificação do diabetes melito do tipo 2. Rio de Janeiro: Diagraphic Editora; 2003.

34 - SARTORELLI D. S, FRANCO L J. Tendências do diabetes mellitus no Brasil: o papel da transição nutricional. Cad de Saúde Pública. Rio de Janeiro. 2003; 19 (1): 529536.

35 - ROSA RS, SCHMIDT MI. Diabetes Mellitus: magnitude das hospitalizações na rede pública de saúde do Brasil: 1999-2001. Epidemiologia e Serviços de Saúde. 2008; 17(2): 123-153.

36 - MALERBI D, FRANCO LJ. The Brazilian Cooperative Group on the study the Prevalence of Diabetes Mellitus and Impaired Glucose Tolerance in the urban Brazilian population aged 30-69 years. Diabetes Care. 1992;15(11): 1509-1516.

37 - TORQUATO MTCG, MONTENEGRO Jr RN, VIANA LAL, SOUZA RAHG, IANNA CMM, LUCAS JCB et al. Prevalence of diabetes mellitus and impaired glucose tolerance in the urban population aged 30-69 years in Ribeirão Preto (São Paulo), Brazil. São Paulo, Med J. 2003; 121(6): 24-30.

38 - GOLDENBERG P, SHENKMAN S, FRANCO LJ. Prevalência de Diabetes Mellitus: diferenças de gênero e igualdade entre os sexos. Rev. Bras. de Epidemiologia; 2003;6(1):18-28.

39 - BRASIL, RIPSA - Rede Interagencial de Informações para a Saúde. Indicadores e Dados Básicos para Saúde. Brasília: Ministério da Saúde; 2005

40 - GARCIA RWD. Reflexos da globalização na cultura alimentar: considerações sobre a alimentação urbana. Revista de Nutrição. 2003; 16(4).

41 - MURRIETA RSS. Dialética do sabor: alimentação, ecologia e vida cotidiana em comunidades ribeirinhas da Ilha de Ituqui, Baixo Amazonas, Pará. Revista de Antropologia. 2001; 44(2): 40-88

42 - MACIEL ME. Uma cozinha à Brasileira. Estudos Históricos. 2004; 33: 1-16.

43 - SAGLYO-YATZIMIRSKY. A comida dos favelados. Estudos Avançados. 2006; 20(58): 123-132.

44 - BRAGA V. Cultura alimentar: contribuições da antropologia da alimentação. Saúde em Revista. 2004; 6(13): 37-44. 
45 - RAYNAUT C. Interfaces entre a antropologia e a saúde: em busca de novas abordagens conceituais. Revista Gaúcha de Enfermagem. 2006; 24(2): 149-165.

46 - POULAIN JP, PROENÇA RPC. O espaço social alimentar: um instrumento para o estudo dos modelos alimentares. Revista Nutricional de Campinas. 2003; 16(3): 245-256.

47 - MINTZ SW. Comida e Antropologia: uma breve revisão. Revista Brasileira de Ciências Sociais. 2001; 16(47): 32-41.

48 - ROTEMBERG S, DE VARGAS S. Práticas Alimentares e o cuidado da saúde: da alimentação da criança e da família. Revista Brasileira de Saúde Matern Infantil. 2004; 4(1): 85-94.

49 - OLIVEIRA SP, THÉBAUD-MONY A. Estudo do consumo alimentar: em busca de uma abordagem multidisciplinar. Revista Saúde Publica. 1997; 31(2): 201-208.

50 - GARCIA RWD. Práticas e comportamento alimentar no meio urbano: um estudo no centro da cidade de São Paulo. Cadernos de Saúde Pública. 1997; 13(3): 445-467.

51 - FREITAS MCS. Educação Nutricional: Aspectos Sócio-culturais. In: Anais do XIV Congresso Brasileiro de Nutrição. CONBRAN-Belo Horizonte. 1986: 1-4.

52 - BIRMAN J. Saúde Coletiva, práticas alimentares e bem estar social. Revista de Saúde Coletiva. 1997; 7(2):7-8.

53 - YPIRANGA L. Delimitação do objeto de trabalho do nutricionista: subsídios para uma discussão. Revista Saúde em Debate. 1989; 29:62-69.

54 - CORNELLI G. Os sentidos da alimentação: para uma antropologia filosófica da alimentação. In: MIRANDA DS, CORNELLI G. Cultura e Alimentação. Saberes Alimentares e Sabores Culturais. São Paulo: SESC, 2007: 25-34.

55 - CARNEIRO H. Comida e Sociedade. Rio de Janeiro: Campus, 2003.

56 - FLANDRIN JL, MONTANARI M. História da alimentação (tradução de Luciano Vieira Machado e Guilherme J. F. Teixeira). São Paulo: Estação Liberdade, 1998.

57 - ROMANELLI G. O significado da alimentação na família: uma visão antropológica. Medicina. 2006; 39(3), 333-339.

58 - CARNEIRO H. História da alimentação no Brasil. In: MIRANDA DS, CORNELLI G. Cultura e Alimentação. Saberes Alimentares e Sabores Culturais. São Paulo: SESC, 2007. p. 71-79.

59 - CASTRO J. Geografia da fome. Rio de Janeiro: Gryphus; 1992.

60 - FREYRE G. Casa Grande \& Senzala. Rio de Janeiro: Record; 1992.28 ed.

61 - CASCUDO LC. História da alimentação no Brasil. Rio de Janeiro: Editora Nacional; 1983. 
62 - CANESQUI AM, GARCIA RWD, (organizadoras). Antropologia e nutrição. Um diálogo possível. Rio de Janeiro: Ed. FIOCRUZ; 2005.

63 - MATOS MAO. Pelas Quebradas, várzeas e chapadas- uma viagem gastronômica pelo Piauí: Teresina: Alínea Publicações Editora; 2007.

64 - DAMASIO D. É feliz quem come aqui! Diário do povo do Piauí 2008; 30 mai.

65 - Lei 8080/90. Dispõe sobre as condições para a promoção e recuperação de saúde, a organização e o funcionamento da serviços correspondentes e dá outras providências. Diário Oficial da União, 1990; 19 set.

66 - Vigilância Epidemiológica. Disponível em http://www.saude.gov.br. Acessado em 18/08/2008.

67 - CARDOSO MHCA, GOMES R Representações sociais e história: referenciais teórico-metodológicos para o campo da saúde coletiva. Cadernos de Saúde Pública. 2000; 16(2): 199-506.

68 - GAZINELLI F et al. Educação em saúde: conhecimentos, representações sociais e experiência da doença. Cadernos de Saúde Pública. 2005; 21(1): 200-206. 
ANEXOS 
Anexo 1

Roteiro de Entrevista Semi-estruturada

- Sexo: $\square$ Feminino $\square \quad \square$ Masculino $\square$

- Idade:

- Nível Educacional:

$\square \square$ Analfabeto

$\square \square$ Ensino Fundamental $\quad \square \square$ Ensino Médio

$\square \square$ Ensino superior

- Ocupação/Profissão:

- Possui vínculo de trabalho: $\square$ Sim $\quad \square$ Não

- Quanta ganha aproximadamente por mês?

- Bairro de procedência:

- Quem encaminhou para o Nutricionista?

$\square$ Médico $\quad \square$ Fisioterapeuta $\quad \square$ outro profissional do PSF $\quad \square$ Por conta própria $\square$ outros

- Uso de medicação: $\square \operatorname{Sim} \quad \square$ Não

Perguntas

1 - Tem aversão (não tolera) algum alimento? Se sim, qual:

2 - Sente-se mal quando come algum alimento?

3 - Tem medo de comer algum alimento?

4 - Já lhe falaram alguma vez que determinado alimento/comida faz mal para diabéticos?

5 - Que tipo de alimento/comida é mais comum na sua casa?

6 - O que mais gosta de comer?

7 - O que significa para você a dieta e a sua saúde?

8 - Quem "cozinha" na sua casa?

9 - Quem mais faz as refeições na sua casa?

10 - Quem compra os alimentos/comida na sua casa?

11 - O que significa para você diet/light?

12 - Já viu/ouviu alguma propaganda de alimento que lhe interessasse?

13 - Conhece algum alimento que seja "bom" para o diabetes?

14 - Fale o que você acha de sua alimentação.

15 - Você tem dificuldades para seguir a dieta que foi planejada para você? Fale sobre isso.

16 - Existe algum alimento que goste muito e que seja controlado em sua dieta?

17 - Existe algum alimento que tenha valor sentimental para você? 